\title{
Short-Term Peak Flow Rate Prediction and Flood Risk Assessment Using Fuzzy Linear Regression
}

\author{
U. T. Khan and C. Valeo* \\ Department of Mechanical Engineering, University of Victoria, Victoria, BC V8W 2Y2, Canada
}

Received March 31 2015; revised 21 July 2015; accepted 30 August 2015; published online December 172017

\begin{abstract}
A fuzzy linear regression (FLR) method is proposed that uses real-time data to accurately predict daily peak flow rate for the Bow and Elbow Rivers in southern Alberta. FLR model performance was compared to a non-fuzzy, error-in-variables model (EIV). Mean daily flow rate, with a delay of one, two, three or seven days was used as the independent variable. In implementing the FLR, a unique hybrid modelling approach was devised that treated peak flow rate as probabilistic and mean daily flow rate as possibilistic. Three gauge errors, $5 \%, 10 \%$ and $20 \%$, were tested and compared to quantify uncertainty in observed flow rate. The research proposed a new method of computing the exceedance probability of peak flow rate using fuzzy numbers. NSE, PBIAS and RSR and a proposed rating system were used to evaluate and compare the methods. Two different calibration schemes were used, including a quasi-real time system. The tests demonstrated that FLR with a one day lag was a very good predictor of peak flow rate and outperformed EIV for two stations on the Bow River. A test dataset from the floods of June 2013 in Calgary was used for risk assessment. The FLR results demonstrated higher flexibility and sensitivity to the flood as it approached Calgary. The fuzzy method was able to capture the peak flow rate for the majority of the high flow rate days, while the EIV model was unable to predict this data within the $95 \%$ confidence interval.
\end{abstract}

Keywords: floods, fuzzy linear regression, peak flow, risk analysis, uncertainty analysis

\section{Introduction}

The June 2013 floods in southern Alberta were one of the worst natural disasters to occur in Canada. The floods were responsible for four deaths, displaced more than $100,000 \mathrm{Al}-$ bertans in over 30 communities (Alberta Government, 2014), and caused approximately $\$ 6$ billion in damage (Environment Canada, 2013). Also, the floods contributed to the transport of large amounts of sediment and the destruction of river banks, channels and aquatic ecosystems (Environment Canada, 2013). This event highlighted the importance and necessity of better flood protection, effective and timely flood mitigation strategies, including improved flood prediction.

The mechanisms behind extreme events in southern Alberta are generally understood and documented (Valeo et al., 2007; Ardell, 2013a); however, predicting and assessing the risk of floods in the future remains a challenge, in part due to the uncertainty in the numerical models that are used. Flood predicttion using physically-based, deterministic hydrologic models (such as a rainfall-runoff routing model) rely on simp-

\footnotetext{
* Corresponding author. Tel.: +001 250 7218623; fax: +1 2507216051 .

E-mail address: valeo@uvic.ca (C. Valeo).
}

ISSN: $1726-2135$ print/1684-8799 online

(C) 2016 ISEIS All rights reserved. doi: 10.3808/jei.201600345 lified, conceptual representation of highly complex, correlated and spatially distributed processes that occur in a watershed (Cox, 2003; Vrugt et al., 2005; Wijiesekera et al., 2012). This leads to considerable uncertainty (Shen et al., 2015). Furthermore, uncertainty in the data used to calibrate model parameters and errors in model structure, compounds this issue (Vrugt et al., 2005).

An alternative to physically-based models is to use datadriven models, which are based on generalized relationships, links or connections between input and output datasets (Solomantine and Ostfeld, 2008). The models can characterize a system with limited assumptions and have similar, if not better performance than physically-based models. In addition, a simpler model structure means that the propagation of uncertainty from different sources is easier to assess. The use of data-driven models, such as neural networks, statistical methods or regression-based techniques (e.g., Li et al., 2015b, Li et al., 2015c; Yang et al., 2015), has been widespread in hydrology, particularly for short term daily flow rate forecasts, using a variety of input variables (Garen, 1992; Zealand et al., 1999; Campolo et al., 1999; Schilling and Walter, 2005; Adamowski and Sun, 2010; Duncan et al., 2011; Li et al., 2015a; Nourani et al., 2015). A recent regression based study predicted flow in the Bow River in Calgary, using a base difference regression model (Veiga et al., 2014). Two-day lead times were used to predict daily flow rates at one station, using data from upstream locations, with promising results. 
Another advantage of using a data-driven approach is that data collected from on-going monitoring systems, e.g. realtime flow rate data that is routinely collected by Environment Canada (Environment Canada, 2014) can be used to calibrate and validate the model, rather than site specific surveys that are required for many physically-based methods.

Data-driven modelling have intrinsic uncertainties associated with it that are not random or probabilistic in nature, thus, making it well suited for the use of fuzzy number theory (Dubois and Prade, 1997; Ozbek and Pinder, 2006). Fuzzy numbers use fuzzy sets (Zadeh, 1965) and possibility theory to describe uncertain or imprecise quantities, measurements or observations (Huang et al., 2010; Zhang and Achari, 2010; Khan and Valeo, 2015). They are more suitable when data is missing, incomplete or vague, combined from multiple sites, and to represent uncertainty that is not purely of a random nature (Bárdossy, 1990; Bárdossy et al., 1990; Bogardi and Duckstein, 2003; Guyonnet et al., 2003; Zhang et al., 2009; Zhang and Achari, 2010; Huang et al. 2010). A major advantage of using fuzzy numbers is that they have the ability to provide more meaningful information compared to traditional techniques, especially in highlighting the possibility and probability of events like floods, and the risk of certain events can be directly estimated from the fuzzy number itself (Khan et al., 2013; Khan and Valeo, 2015). Fuzzy numbers are based on possibility theory, which suggests that some of the strict assumptions in many probability models can be relaxed, thus, making it useful for hydrological systems (Peters, 1994; Kim et al., 1996; Kahraman et al., 2006). The consistency principle (Zadeh, 1978; Dubois et al., 1993) links possibility and probability, implying that something has to be possible before it is probable. A number of methods have been created that utilize this principle to convert observed data into fuzzy numbers (Oussalah, 2000).

Fuzzy numbers have been widely used in hydrology to represent uncertainty in the parameters of numerical models (Khan et al., 2013; Khan and Valeo, 2015). The literature demonstrates the utility and advantage of using fuzzy numbers and a summary of some of these applications can be found in Khan and Valeo (2015). Fuzzy numbers have also been used in conjunction with data-driven models to predict flow rate in rivers. Alvisi and Franchini (2011) developed a method to use fuzzy numbers for the weights in an artificial neural network algorithm to predict water level and discharge under uncertainty. Corani and Guariso (2005) proposed an artificial neural network and fuzzy logic based method for river flood predicttions that used a weighted least squares training algorithm, rather than the use of fuzzy numbers. Nguyen and Chua (2012) used a recursive adaptive network-based fuzzy inference system for real-time flood forecasts, with lead times between 1 to 5 days. Results from this model were better compared to a physically-based model used for comparison. Also, Wang and Huang (2013) used a two-stage mixed-integer linear programming approach to develop a model for flood-diversion planning. They represented uncertainties in the system using a fuzzy based approach. Similarly, Wang et al., (2014) used a possibility-probability hybrid approach to represent multiple un- certainties in a flood management system. In addition to this, Ahmad and Simonovic (2011, 2013 and 2015) use a 3D fuzzy set approach to assess spatial and temporal variability of urban flood damage and risk assessment. Abdalla et al. (2014) used a fuzzy based method to quantify the uncertainty in flood risk assessment. Lohani et al. (2014) proposed a Takagi-Sugeno fuzzy inference system that uses cluster analysis, to predict floods using hourly data (rainfall and flow rate). These type of fuzzy rule based analysis has been quite successful for flood forecasting (Zhang et al., 2012), but conceptual differ from a fuzzy number based approach. As described above, a fuzzy number based method is when the uncertainty in a para- meter is represented through a specific type of fuzzy set based on possibility theory.

While the benefits of a fuzzy number based approach for flow rate prediction have been investigated, the use of fuzzy linear regression (FLR) to predict peak flow rate has not been explored. FLR is a method used to extend simple linear regression for applications involving fuzzy numbers, i.e. for uncertain or imprecise systems (Khan and Valeo, 2015). This property makes them ideally suited for data-driven techniques that model environmental systems. It provides an alternative method when simple linear regression may not be possible, e.g. when assumptions of simple linear regression are not met (including when the assumption of linearity is invalid), or if there is obvious fuzziness or uncertainty in the underlying data or process coefficients (Savic and Pedrycz, 1991; Chang and Ayyub, 2001). FLR tries to capture the vagueness, and the non-random or fuzzy error in the model structure: it is assumed that deviations are due to system fuzziness, i.e. the fuzziness of the regression coefficients (Chang and Ayyub, 2001). In simple linear regression models, the independent variable $x$ predicts dependent variable $y$ and in ordinary least squares regression, it is assumed that $x$ are observed without error (i.e. they are fixed). This assumption is typically only true when the independent variables are controlled and the effect on the dependent variable is measured. Often in engineering applications, the dependent data are observed with an error, or bias, or are random rather than fixed (Maddala, 1988). This introduces a bias in the model coefficients such that the least squares estimates of the regression coefficients will be underestimated (Fuller, 1987; Maddala, 1988). Unlike a traditional simple linear regression model, FLR allows uncertainty in the input parameters to be included in the analysis. The benefit of using a fuzzy number based approach with a data driven method (FLR) to predict flow rate is that real-time data, which is often routinely collected, can be used to accurately predict peak flow rate. The uncertainty in the system and in the data can be collectively represented in a fuzzy number. A risk analysis can then be directly conducted using fuzzy numbers to assess the risk of flow magnitudes beyond a given threshold.

The objectives of this research is to improve peak flow rate prediction, and flood risk assessment, in southern Alberta, using a data-driven method in order to provide water resource managers sufficient lead time (e.g. between one and seven days) to implement flood defence systems. Data from three sites on two rivers (the Bow River and Elbow River) which 
flow through Calgary, Alberta are used. Currently, the Government of Alberta provides information to municipalities, including Calgary, which are at risk of flooding. This includes real-time and daily flow forecasting (Walford, 2014), which is required, for example, by the City of Calgary to empty the Glenmore Reservoir (on the Elbow River) in the event of a risk of a large flood (City of Calgary, 2014). A number of factors impact the accuracy of these predictions during extreme events, including the use of data from hundreds of different sites, lack of knowledge of the precise magnitude and location of upstream precipitation, the destruction of upstream monitoring stations, and uncertainty with meteorological forecasts (Ardell, 2013a; Ardell, 2013b; Walford, 2014).

Thus, there is a need for improved real-time flow rate predictions, particularly with respect to the timing and magnitude of the peak flow rate, to help mitigate against the impacts of the floods, as experienced in 2013. An FLR method (developed in in Khan and Valeo, 2015) is proposed that uses realtime data to predict daily peak flow rate using lagged daily flow rate. This approach retains the simplicity and benefits of simple linear regression, but with the ability to incorporate uncertainty that improves risk assessment and the prediction of extreme floods. This FLR method is unique because fuzzy number inputs, outputs and regression coefficients are used, whereas other fuzzy regression techniques only use fuzzy representations for some (not all) of these parameters (Khan and Valeo, 2015). In addition, this method uses probability-possibility transformation to define fuzzy numbers with uniquely non-linear membership functions; this is much more suitable for analysis of flow rate.

The results from this analysis are compared to observations, as well as the results from an error-in-variables (EIV) regression model. Both these methods attempt to describe an uncertain system with an error in the observations (Bárdossy et al., 1990) using a relatively simple data-driven model, with the key difference that one method is based on probability theory (EIV) while the other is based on possibility theory (FLR).

\section{Methods}

\subsection{Data Collection: Site Description and Selection Criteria}

The Bow River basin, located in southern Alberta, has an area measuring approximately $25,123 \mathrm{~km}^{2}$ and provides significant economic activity in the form of supplying drinking water for a major urban centre (the City of Calgary), and irrigation water for several irrigation districts in the Prairie region in Alberta (BRBC, 2010a). For this research, three monitoring sites in the Bow River basin were selected for peak flow rate prediction and flood risk assessment. These sites are: "Bow River at Banff" (Environment Canada WSC Station ID: 05BB 001), "Bow River at Calgary" (ID: 05BH 004), and "Elbow River at Bragg Creek" (ID: 05BJ004). The first two sites are located on the Bow River, whereas the last is located on the Elbow River (a tributary that merges with the Bow River in downtown Calgary); see Figure 1 below for the relative location of each site in Alberta.

The Bow River originates in Bow Lake, located in the Rocky Mountains and flows south-easterly through Banff (drainage area of $2210 \mathrm{~km}^{2}$ ) and Calgary (drainage area of $7870 \mathrm{~km}^{2}$ ), meeting the Oldman River, and ultimately draining into Hudson Bay (Robinson et al., 2009; Environment Canada, 2014). The Bow River averages a $0.4 \%$ slope over its $645 \mathrm{~km}$ length, measuring as high as $7 \mathrm{~m} / \mathrm{km}$ in the Rocky Mountains (BRBC, 2010a; BRBC, 2010b). The Bow River is supplied by precipitation accumulated in the snowpack in the Rocky Mountains, precipitation and discharge from shallow groundwater. Runoff peaks in the spring (typically in June) while low flows are seen in the winter (January) (BRBC, 2010 b). While the River is unregulated at the Banff monitoring station, Bearspaw Dam regulates flow immediately upstream of

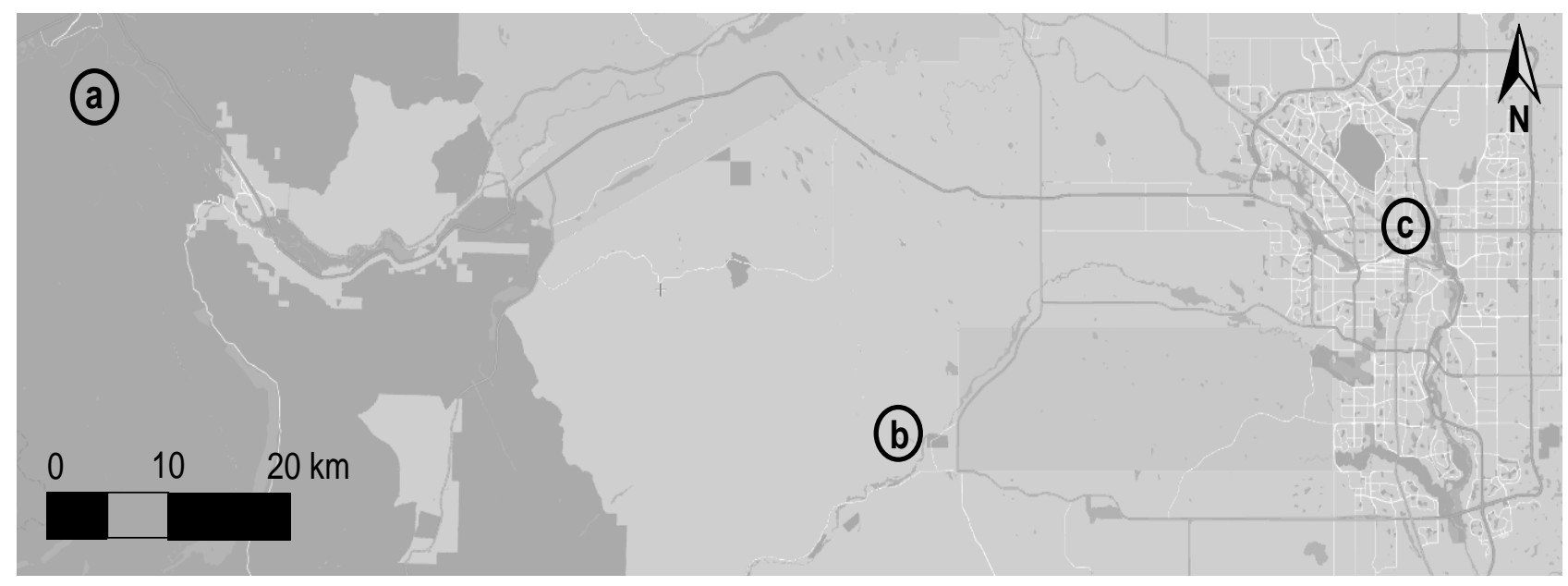

Figure 1. The locations of the three sites used in this research: (a) Bow River at Banff, (b) Bragg Creek at Elbow River, and (c) Bow River at Calgary. 
Calgary city limits. The headwaters of the Elbow River are located at Elbow Lake in the Rocky Mountains. The river flows easterly, through the hamlet of Bragg Creek (drainage area of $791 \mathrm{~km}^{2}$ ), and merges with the Bow River in downtown Calgary. The Elbow River has an average grade of $1 \%$ over its $124 \mathrm{~km}$ length; the total drainage area of the Elbow River sub-basin is $1235 \mathrm{~km}^{2}$ (BRBC, 2010b; BRBC 2010c; Environment Canada, 2014). The Glenmore Dam in Calgary regulates the downstream flow of the Elbow River through Calgary. These rivers flow through many residential communities and the commercial centre of Calgary. Thus, the importance of peak flow prediction and flood risk assessment of these rivers is extremely important for the safety of the residents in Calgary, and for protection of significant assets in downtown Calgary.

Eleven years of hourly flow rate data for each station was obtained from Environment Canada for the period January 1, 2000 to December 31, 2010. The annual median flow rate at Banff, Calgary and Bragg Creek varied between $11-26 \mathrm{~m}^{3} / \mathrm{s}$, $47-85 \mathrm{~m}^{3} / \mathrm{s}$, and $4-8 \mathrm{~m}^{3} / \mathrm{s}$, respectively for the selected period. The annual peak flow rate at Banff, Calgary and Bragg Creek varied between $142-306 \mathrm{~m}^{3} / \mathrm{s}, 172-787 \mathrm{~m}^{3} / \mathrm{s}$, and $15-$ $307 \mathrm{~m}^{3} / \mathrm{s}$, respectively. The highest peak flow rate at Banff $\left(306 \mathrm{~m}^{3} / \mathrm{s}\right)$ occurred in 2007, and in 2005 for Calgary (787 $\mathrm{m}^{3} / \mathrm{s}$ ) and Bragg Creek $\left(307 \mathrm{~m}^{3} / \mathrm{s}\right)$. The peak flow rates in 2005 are associated with a flood event in Calgary and southern Alberta, which estimated to have cost approximately \$400 million in damage (Environment Canada, 2005; Valeo et al., 2007). This flood event was the last major flood in southern Alberta prior to the floods in June, 2013. It is important to note that though the drainage area at Bragg Creek is almost three times smaller than the drainage area at Banff, the maximum annual peak flow for these sites is similar, and the median annual flow at Bragg Creek is much lower than the peak flow rate, indicating that this site is prone to flash flooding.

The hourly flow rate collected for each site was filtered by removing dates where shift corrections (usually due to ice conditions) were applied by Environment Canada. Typically for the eleven year period, the data ranged between midMarch to early-November for Banff and Calgary, and from mid-February to late October for Bragg Creek. Any data points within the selected range that had corrections applied were removed from further analysis. In addition to this, a second filter was applied to remove the low flow rate periods, since the primary objective of this research was to predict peak flow rates. To do this, the first and last day where the daily peak flow rate was greater than the ice-free median flow rate were used as the lower and upper limits of the data range, respectively. This reduced the data from an original, unfiltered set of 4018 days of hourly flow rate data to 1583 days for Banff, 1860 for Calgary, and 1633 for Bragg Creek, i.e. representing about $40 \%$ of available data.

The filtered data was used to calculate the daily peak flow rate $\left(Q_{P}\right)$. An initial correlation analysis was conducted using $Q_{P}$ and several other variables, including daily mean flow rate $\left(Q_{D}\right)$, daily precipitation, lagged $Q_{P}$, (computed at different lags between one to seven days), and various combinations of these variables as well. This preliminary analysis showed that while an auto-regressive approach (using lagged peak flow rate) to predict $Q_{P}$ showed promise, a better overall performing model structure was to use $Q_{D}$ at different lags. This was based on the magnitude of the correlation coefficient for each site at differrent lags. It should be noted that a similar analysis was conducted using upstream data (i.e. at Banff) to predict peak flow rate downstream (i.e. at Calgary), and lower correlations were found for the entire study period using upstream data rather than local data (correlation coefficient of 0.82 vs. 0.95 on average, respecttively). Details of this analysis, including different combinations of variables tested as the independent variable, are not discussed here but may be found in Khan (2014) and Khan and Valeo (2014). Thus, these two variables were used to construct the EIV and FLR regression models to predict $Q_{P}$, in the form of:

$Q_{P}(t)=f\left(Q_{D}(t-d)\right)$

where $Q_{P}(t)$ is the daily peak flow on day $t, Q_{D}(t-d)$ is the mean daily flow on day $t-d$, and $d$ is the lag in days, selected as either 1, 2, 3 or 7 days for this research. These lags were specifically selected to give sufficient lead time to operators of the proposed method to enact flood defence systems in a timely manner. The 7 day lag represents the limit of the applicability of the proposed method. Model performance is expected to diminish in proportion to the number of lag days between a lag of 3 and 7 days, thus, analysis for lags of 4,5 or 6 days is not included.

\subsection{Error-in-Variable Linear Regression}

A simple linear regression model is proposed to predict $Q_{P}$ using $Q_{D}$ at different lags. However, ordinary least squares regression assumes that the independent variables (in this case $Q_{D}$ ) are observed without error (i.e. they are fixed). This assumption is only true for controlled experiments, and not when monitoring data is being used to find suitable relationships between variables. The bias introduced by this error results in an underestimation of regression coefficients, even for very large samples (Fuller, 1987; Maddala 1988). Thus, to account for the uncertainty in the calculated $Q_{D}$ being used to predict $Q_{P}$, an EIV regression model is specified as follows:

$Q_{P}=A+B Q_{D}$

where $Q_{P}$ is the daily peak flow rate of interest, $A$ and $B$ are the regression coefficients to be calculated, and $Q_{D}$ is the calculated mean daily flow rate (i.e., the average of the 24 hourly data points observed). The authors propose that this calculated $Q_{D}$ is not the true mean daily flow rate, but a value with uncertainty. The true mean daily flow rate $\Phi_{\mathrm{D}}$ is given by:

$\Phi_{D}=Q_{D}+u$ 
where $u$ is a random error term, which we assume to be the standard error of the mean, estimated as:

$u= \pm T \frac{\sigma}{\sqrt{n}}$

where $T$ is the $t$-statistic for 23 degrees of freedom, $\sigma$ the standard deviation of the observations of hourly flow rate and $n$ (which equals 24) is the number of data points. Therefore, for each calculated $Q_{D}$ (mean of observations), we also calculate the daily standard deviation $(\sigma)$ and then calculate the daily error $(u)$. By taking this uncertainty in the calculated mean daily flow rate, an unbiased estimate of the slope coefficient $B$ can be calculated by:

$$
B=\operatorname{COVAR}\left(Q_{D}, Q_{P}\right) /\left(\operatorname{VAR}\left(Q_{D}\right)-\operatorname{VAR}(u)\right)
$$

The constant $A$ can be estimated from $\left(Q_{P}-B Q_{D}\right)$. Once the regression coefficients have been calculated, the unbiased estimate of the variance of the predictions, and the confidence interval of the predictions can be calculated using the standard procedure (Wittink, 1988). The derivation of this EIV regression method is widely available in many regression or econometric textbooks with good descriptions in Fuller (1987) and Maddala (1988). It is worth noting here that the similarity of EIV and FLR is that they both attempt to consider error in the observations. The differences between the two is that the basic assumptions of each method are completely distinct: the error in EIV is assumed to be the same for all values, whereas in the fuzzy case each value will have its own membership function, and the data requirements for the EIV are higher (Bárdossy et al., 1990).

Typically, after a regression analysis has been conducted, an analysis of residuals must be conducted to ensure that the initial assumptions of the model have not been violated. The four principal assumptions of linear regression are: (i) the mean of residuals $r$ is zero, $E(r)=0$; (ii) the residuals have a constant variance (with respect to time, and the data), $\operatorname{var}(r)=$ $\sigma^{2}$; (iii) the residuals are independent or uncorrelated, $\operatorname{cov}\left[\left(r_{1}, r_{2}\right)\right]=0$; and (iv) the residuals are normally distributed, $r \sim N\left(0, \sigma^{2}\right)$. Of these assumptions, the third assumption (autocorrelation of the residuals) is most important for time series data (such as the dataset considered in this research). A violation of this assumption, however, is not critical if the first assumption holds. Then, the presence of significant autocorrelation suggests that though the regression coefficient estimates are still unbiased, they are no longer the most efficient estimates, in other words they are not minimum variance estimates (Wittink, 1988; Montgomery et al., 2006). This means that the predicted variance of the coefficients is lower than the actual variance, the standard error is artificially low, and that the coefficient of determination is artificially higher. Thus, the presence of significant autocorrelation will show a stronger relationship between the dependent and independent variables than what truly exists, and the use of confidence intervals and hypotheses testing may not be appropriate (Montgomery et al., 2006).

\subsection{Fuzzy Linear Regression}

The objective of the FLR method is similar to the ordinary least squares approach to linear regression, however, instead of minimizing the residual between an observed and regressed value, the distance between two fuzzy numbers is minimized instead. Given a set of fuzzy observations $\tilde{Q}_{d_{i}}$ and $\tilde{Q}_{p_{i}}$, and their corresponding membership functions, $\mu\left(\tilde{Q}_{d_{i}}\right)$ and $\mu\left(\tilde{Q}_{p_{i}}\right)$, for $(i=1,2, \ldots, n)$ a regression model is defined as:

$\tilde{Q}_{p}=\tilde{A}+\tilde{B} \tilde{Q}_{d}$

where the coefficients $\tilde{A}$ and $\tilde{B}$ are fuzzy numbers. The objecttive is to solve the following least-squares optimization problem:

$\min r(\tilde{A}, \tilde{B})=\sum_{i=1}^{n} d^{2}\left(\tilde{Q}_{p_{i}}, \tilde{A}+\tilde{B} \tilde{Q}_{d_{i}}\right)$

where $d^{2}\left(\tilde{Q}_{p_{i}}, \tilde{A}+\tilde{B} \tilde{Q}_{d_{i}}\right)=\bigcup\left[\tilde{Q}_{p_{i}}-\tilde{A}-\tilde{B} \tilde{Q}_{d_{i}}\right]_{\mu}$ for $i=1,2, \ldots, n$ and $\mu=0$ to 1 . The metric $d$ measures the sum of the squared-deviations of the observed $\left(\tilde{Q}_{p_{i}}\right)$ and predicted $\tilde{A}+\tilde{B} \tilde{Q}_{d_{i}}$ intervals $[\ldots]_{\mu}$, for all $\alpha$-cuts between $\mu=0$ and $\mu=$ 1. Using fuzzy arithmetic ensures that the coefficients $\tilde{A}$ and $\tilde{B}$ are normal and convex, a requirement of fuzzy numbers.

Using the FLR method means that the output of the method is also a fuzzy number, in this case a set of values corresponding to the upper and lower limits of $\alpha$-cuts at $0,0.25,0.5$, 0.75 , and 1 . These five levels were selected to give a full spectrum of possible values of the fuzzy number. The predicted membership value can be used to calculate the exceedance probability of a value within the fuzzy set using a possibility to probability transformation. This is useful since probabilities are more readily understood by water resource managers and the general public. A description of a probability to possibility transformation and its inverse are described below.

\subsubsection{Probability to Possibility Transformations}

A number of different methods exist to create fuzzy numbers from observed data; these methods are known as probability-to-possibility transformations. A recent summary of different conceptual approaches to these transformations is provided in Mauris (2013). For this research a method by Dubois et al. (2004) is adapted and implemented to convert the subdaily flow rate observations to $Q_{P}$ and $Q_{D}$ into fuzzy numbers. This method was designed to convert a uni-modal discrete probability distribution to a triangular fuzzy set. It was adapted by Khan and Valeo (2014) to create non-linear discrete fuzzy numbers. The basic premise of this transformation is to convert a non-specific probability distribution to a membership function where the modal value has a $\mu=1$, and the su- 
pport (the limits of the $\alpha$-cut interval) is calculated using an uncertainty value $e$ (details of this value are discussed below). The values of the fuzzy number at other membership levels are calculated using a relationship between the probability and possibility that matches the area under the probability density function (pdf) to the highest membership level.

To convert the observed $Q_{D}$ and $Q_{P}$ to fuzzy numbers, two different approaches were taken. For $Q_{D}$, a non-specific probability distribution was converted to a fuzzy number using the method described above. Hourly observations ( 24 points), the modal value (where the membership level was equal to one) and a support calculated using an uncertainty value $e$ (details of this are given below) were used. For $Q_{P}$, a specific pdf (assumed to be a Normal distribution, with the mean value as the observed peak flow rate for a given data, and a variance calculated using the error value $e$ ) was used to construct a fuzzy number using the method outlined above. This represents a hybrid modelling approach, where a probabilistic parameter $\left(Q_{P}\right)$ is used with a possibilistic parameter $\left(Q_{D}\right)$ in one regression model.

\subsubsection{Significance of the Error Value $e$}

The value of $e$ used for these transformations represents the uncertainty associated with the measured flow rate. Typically, analysts assume that the in situ measured data from river flow rate measurements (such as that provided by Environment Canada) are within $\pm 5 \%$ of the true value at the $95 \%$ confidence interval (Hamilton and Moore, 2012; Papa et al., 2012). Others consider that this random uncertainty associated with the measurement of the flow rate to be negligible (Baldassarre and Montanari, 2009) or as low as $1 \%$ of the true value at the $95 \%$ confidence interval (Shrestha and Simonovic, 2010). However, if other components of uncertainty associated with determining flow rate are included (e.g. stagedischarge relationship, shape of river bed, etc.), this accuracy declines significantly. Many in the research community advocate for uncertainty levels between 15 and $20 \%$ of the true value (Papa et al., 2012), with 15\% considered as "optimistic" (Baldassare, 2012). McMillan et al. (2012) provide a list of typical quantitative results of combined flow rate uncertainty. In one studies this uncertainty is listed as high as $100 \%$ for low flows, $10 \%$ for medium flows, and $20 \%$ for high flows (Krueger et al., 2010; McMillan et al., 2012). Daily discharge uncertainty is listed with a range of $\pm 100-200 \%$ for low flows and $\pm 100 \%$ for high flows by Harmel and Smith (2007) and up to $50 \%$ by Hamilton and Moore (2012) for all magnitudes. Pappenberger et al. (2006) reported uncertainty with peak flow rates to range between 8 and 25\%, Baldassare and Montanari (2009) reported a range from $6.2 \%$ to $42.8 \%$ at the $95 \%$ confidence interval, and Westerberg et al. (2011) give a range between -43 to $73 \%$.

The literature shows a very wide range of error values, with little consensus on the optimal value. Thus, three differrent error values, $e$, were selected for this research: $5 \%, 10 \%$ and $20 \%$ and the analysis was conducted using each value. These values represent a conservative estimate of flow rate uncertainty, which have been selected to demonstrate the application of a fuzzy number based method and for comparison with a probabilistic method; the authors recognize that the value of $e$ is not limited to only these values (i.e. higher $e$ values can be used). The $5 \%$ represents the case where only random uncertainty is considered, whereas the $20 \%$ represents the case for high flow rates, which are of primary interest for this research. In another application using fuzzy number analysis to quantify and characterize peak flow rate, Shrestha and Simonovic (2010) used an error value of 50\% to represent the support of the fuzzy number: thus, the selected values of $e$ in this research are within a conservative range. Figure 2 below shows examples of the $Q_{D}$ and $Q_{P}$ transformations for an $e$ value of $20 \%$.

\subsubsection{Possibility to Probability Transformations}

Defuzzification, or transforming the possibility distribution of a fuzzy number to a probability distribution, is important when an estimate is needed on whether something is "probable" rather than "possible". For example, while fuzzy regression might give a prediction of future peak flow rate as a fuzzy number, an estimate of the probability associated with the magnitude of peak flow rate is needed, often to communicate the risk of a flood. For example, a fuzzy number might predict that the peak flow rate to be $500 \mathrm{~m}^{3} / \mathrm{s}$ with a membership level equal to 0.75 , but a decision maker might need to know how likely a flow rate of that magnitude is, before making a decision. For this case, an inverse transformation can be used to calculate the point estimate of probability for any given value (based on Oussalah, 2000 and Dubois et al., 2004). However, in most hydrological applications, we are interested in exceedance probability $P(x>X)$ rather than probability of a single event $x$. Thus, an inverse transformation to calculate the exceedance probability was developed specifically for non-symmetric fuzzy numbers for discrete systems.

For any $x$ in $X$ in the support of a fuzzy number $[a, b]$, we have the corresponding membership level $\mu(x)$ and the paired value $\mu\left(x^{\prime}\right)$ which also shares the membership level. The value $\mu(x)$ is the sum of the cumulative probability distribution between $\left[a, x^{\prime}\right]$ and $[x, b]$, labelled $A_{L}$ and $A_{R}$, respectively:

$\mu(x)=A_{L}+A_{R}$

where $A_{R}$ represents the exceedance probability that the predicted value is greater than $x$. Given the fact that the fuzzy number is not symmetrical, we use the lengths of the two intervals $\left[a, x^{\prime}\right]$ and $[x, b]$ to establish a relationship between $A_{L}$ and $A_{R}$. Using this ratio, we can estimate $A_{\mathrm{R}}$ as:

$A_{R}=P(x>X)=\mu(X) /\left[1+\left(x^{\prime}-a\right) /(b-x)\right]$

Thus, this predicted value $P(x>X)$ can be used by water resource managers to determine if there is a serious risk of high peak flow rate in the predicted time period, and if it 

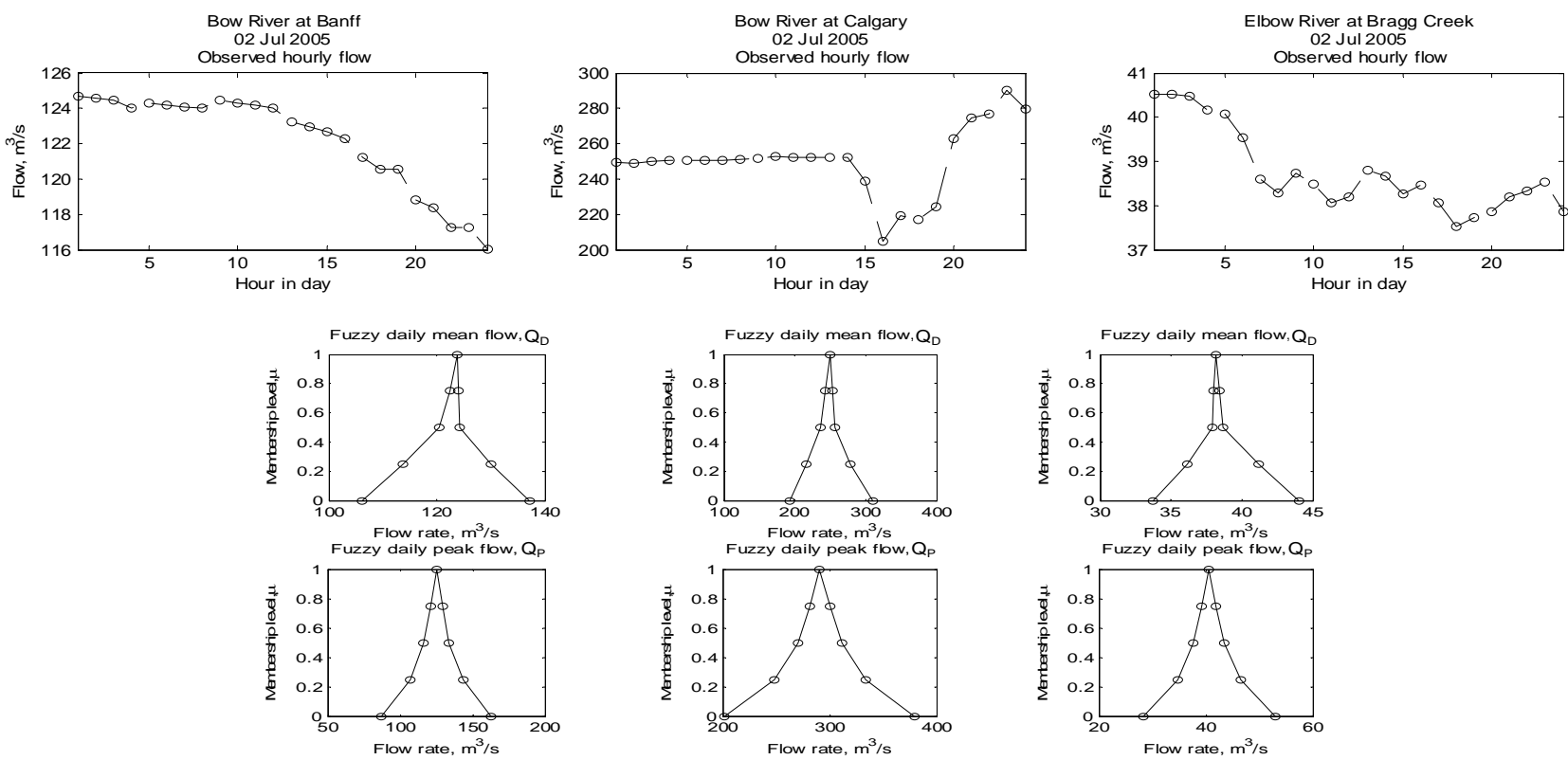

Figure 2. A sample of results of transforming observed hourly flow rate to fuzzy mean daily flow rate, and fuzzy mean peak flow rate, for July 2, 2005. An $e$ value of $20 \%$ was used for these conversions.

warrants the implementation of flood defence strategies. For this research a flow rate magnitude corresponding to the $2 \%$ flow rate $\left(Q_{P 2} \%\right)$ for the eleven year period (from 2000 to 2010) was calculated for each site. This value, $Q_{P 2} \%$ is exceeded $98 \%$ of the time in the eleven year period at each site. These values were $173 \mathrm{~m}^{3} / \mathrm{s}$ at Banff, $305 \mathrm{~m}^{3} / \mathrm{s}$ at Calgary, and $59 \mathrm{~m}^{3} / \mathrm{s}$ at Bragg Creek. These values were then used to establish the probability of predicted peak flow rate for a given day to be higher than $Q_{P 2} \%$. This procedure can be used by decision makers to create a set of rules relating to flood risk management. For example, if there is more than a $5 \%$ chance of the predicted flow to be greater than $Q_{P 2 \%}$, a flood defence warning is issued.

\subsection{Quantifying Model Performance}

Three metrics are used to quantify and compare the performance of the EIV and FLR model. These are the NashSutcliffe efficiency (NSE) (Nash and Sutcliffe, 1970), percent bias (PBIAS), and the ratio of the root mean square error to the observed standard deviation (RSR). If a data set of observations $y_{i}$ has a mean $\bar{y}$ and corresponding predictions at each point $i$ denoted by $y_{i}^{\text {pred }}$ then:

$$
\begin{aligned}
& N S E=1-\left(\sum_{i=1}^{n} y_{i}-y_{i}^{\text {pred }}\right) /\left(\sum_{i=1}^{n} y_{i}-\bar{y}\right) \\
& P B I A S=100\left(\sum_{i=1}^{n} y_{i}-y_{i}^{\text {pred }}\right) /\left(\sum_{i=1}^{n} y_{i}\right) \\
& R S R=\sqrt{\sum_{i=1}^{n}\left(y_{i}-y_{i}^{\text {pred }}\right)^{2}} / \sqrt{\sum_{i=1}^{n}\left(y_{i}-\bar{y}\right)^{2}}
\end{aligned}
$$

These metrics were calculated for each crisp and fuzzy simulation. For the fuzzy data, the metrics were calculated at each membership level $(\mu=0,0.25,0.50,0.75$ and 1$)$. How- ever, this meant that for each metric, there were five intervals of metric values for each fuzzy number (corresponding to each membership level), making it difficult to compare results between the crisp and fuzzy results. Thus, a rating system developped by Moriasi et al. (2007) was extended for use with fuzzy numbers. We assign a numerical value to each of the qualitative ranks provided by Moriasi et al. (2007), as listed in Table 1. For each fuzzy number, each metric was calculated at each membership level, and assigned a rating value according to Table 1. The overall metric for each fuzzy number was then the average of the five (corresponding to each $\mu$ ). Furthermore, this rating was assigned to each of the calculated metrics for the crisp results to enable a quantitative comparison between models.

To directly compare the crisp and fuzzy results, these metric ratings were then combined to give an "average rating" (AR) of each model: this was the average of the rating (i.e. $0,0.33,0.66$ and 1) of each metric (NSE, RSR or PBIAS). The AR were then assigned a qualitative rating similar to Moriasi et al. (2007) for comparison and are shown in Table 2.

Once this step was completed for all metrics (NSE, RSR and PBIAS) an overall rating was calculated by using the same rating table. In doing so, one model could be compared to another by the use of only one overall metric. This system was used to make more direct comparisons between different models (i.e. models at differrent lags, or with different error values).

In addition to these three metrics, a performance metric, $D$, was calculated for the risk analyses stage of this research. $D$ measured the relative difference between the observed peak flow rate and upper limit of either the fuzzy support, or the $95 \%$ confidence interval, for events where the observed peak 
Table 1. Rating System Used to Rank and Compare Performance of the Models (Adapted from Moriasi et al., 2007)

\begin{tabular}{lllll}
\hline Description & NSE & RSR & PBIAS & Rating \\
\hline Very good & $0.75<\mathrm{NSE} \leq 1.00$ & $0.00<\mathrm{RSR} \leq 0.50$ & PBIAS $\leq|10| \%$ & 1 \\
Good & $0.65<\mathrm{NSE} \leq 0.75$ & $0.50<\mathrm{RSR} \leq 0.60$ & $|10| \% \leq \mathrm{PBIAS}<|15| \%$ & 0.66 \\
Satisfactory & $0.50<\mathrm{NSE} \leq 0.65$ & $0.60<\mathrm{RSR} \leq 0.70$ & $|15| \% \leq \mathrm{PBIAS}<|25| \%$ & 0.33 \\
Unsatisfactory & $\mathrm{NSE} \leq 0.5$ & $\mathrm{RSR} \geq 0.50$ & PBIAS $\geq|25| \%$ & 0 \\
\hline
\end{tabular}

flow rate was greater than the $Q_{P 2 \%}$. The objective of calculating and then comparing this metric was to determine which model performed better (i.e. was closest in magnitude to the observation) in cases where both models underpredicted the observed peak flow rate. The distance was calculated as:

$$
D=\left|y_{\text {upper }}-y_{i}\right|
$$

where $y_{\text {upper }}$ is either the upper limit of the fuzzy support []$_{\mu}=$ 0 , or the $95 \%$ confidence interval.

\subsection{Model Implementation}

Two distinct modelling approaches were taken. In the first phase, two proof-of-concept models (one using EIV method, the second using the fuzzy method) were constructed using the entire dataset, at different lags. In the second phase, a recursive algorithm was employed for both regression methods, where an additional year of data was sequentially added to the models, and updated the model parameters. The purpose of the first phase is to show the global appropriateness of the data driven technique to predict peak flow rate and quantify the performance of both regression methods. The purpose of the second method is to demonstrate the utility of the methods in a quasi-real-time state. Lastly, the final version of the recursive model was then used for a test data set comprised of the 2013 flood year in Alberta.

\subsubsection{Proof-of-Concept Models}

A proof-of-concept model was constructed for both the EIV regression method and the FLR method at each of the three sites. In each case, six years of data was used for model construction, specifically data from 2000, 2002, 2004, 2006, 2008 and 2010. Model validation was done using another five years of data, specifically, 2001, 2003, 2005, 2007 and 2009. The flood year of 2005 was not included in the calibration. This modelling exercise was conducted at four different lags, (i.e. lagged $Q_{D}(t-d)$ ) where $d=1$ day, 2 days, 3 days or 7 days. In addition to this, three different error values, $e$, were used for fuzzy number construction, namely $e$ of $5 \%, 10 \%$ and $20 \%$. Thus, a total of 12 models were constructed and validated at each of the 3 sites (with 4 lags and 3 error values). Error analyses were conducted for each model.

\subsubsection{Recursive Models}

For each type of regression model, the recursive modelling set started with using data from the year 2000 for calibration, and data from the year 2001 for validation. An error analysis was then conducted for both model types. Following this, the calibration dataset was updated to include the years 2000 and 2001, while the validation dataset used data from the year 2002; the regression parameters were updated and another error analysis was conducted. This process was continued until ten years of data were used for calibration, and the final year (2010) was used for validation. This meant a total of ten models were constructed and validated for each of the three sites, at four different lags (1, 2, 3 and 7 days), at three error values $(5,10$, and $20 \%)$. The rating system described earlier was used to condense the results from the error analyses on each model to ease comparison between different simulations.

A risk analyses was then conducted on days when the observed flow was higher than $Q_{P 2} \%$. It should be noted that for each case where this was true, the predicted flow from the validation dataset was used for the analysis. For brevity's sake this analysis was only conducted on models that used a 1 day lag for $Q_{D}$, and an error value $e$ of $20 \%$, for each site.

\subsubsection{Test Case}

To test the developed models, an independent dataset was used. This was daily peak flow rate and daily mean flow rate at Calgary for the year 2013, which was an extreme flood year in southern Alberta. Regression coefficients from the last recursive model, i.e. where ten years of data from 2000 to 2009 was used for model construction, was used to predict peak flow rate using the 2013 mean daily flow rate (only with a lag of one day, and an error value of $20 \%$ ). An error analysis between the observed and predicted peak flow rate was conducted. Following this a risk analysis was conducted on the days in 2013 where the observed peak flow rate was higher than the historical (i.e., the 2000 - 2010 period) $Q_{P 2} \%$.

\section{Results and Discussion}

\subsection{Model Performance Comparison}

\subsubsection{Proof-of-Concept}

The proof-of-concept models were constructed using 6 years of data, and validated using 5 years of data. These mo-

Table 2. Rating System Used to Compare the Average Rank of each Simulation

\begin{tabular}{ll}
\hline Description & Average Rating \\
\hline Very good & $\mathrm{AR}>0.9$ \\
Good & $0.66<\mathrm{AR} \leq 0.9$ \\
Satisfactory & $0.33<\mathrm{AR} \leq 0.66$ \\
Unsatisfactory & $0.0<\mathrm{AR} \leq 0.33$ \\
\hline
\end{tabular}


dels were constructed at each of the 4 lags, and 3 error values, for each site. Figures 3 to 5 shows sample results for one particular model: Bow River at Calgary, with a lag of 1 day and $e$ of $20 \%$. Figure 3 shows the trend plots of two years, 2010 (which was used for calibration, and is one of the lowest flow years in the dataset) and 2005 (which was used for validation and was a flood year). The figure shows that in general the observed peak flow rate falls within the $95 \%$ confidence interval (CI) and within the interval defined by the $\alpha$-cut at $\mu$ $=0$. For the Bow River at Banff site, the amount of observations captured within the predicted fuzzy interval (at $\mu$ $=0$ ) for lags of 1, 2, 3 and 7 days were 92.6, 82.2, 79.9 and $57.1 \%$, respectively. At the Bow River at Calgary site, the amount of observations captured within the predicted fuzzy interval (at $\mu=0$ ) for lags of 1, 2, 3 and 7 days were 97.2 92.1, 85.2, and 72.1\%, respectively. Lastly, at the Elbow River at Bragg Creek site, the amount of observations cap- tured within the predicted fuzzy interval (at $\mu=0$ ) for lags of $1,2,3$ and 7 days were $91.0,84.3,82.1$, and $71.3 \%$, respectively. These results show that there was minimal im- pact of the lead time or peak flow prediction timing since for the majority of events (especially at low lags), the observa- tions fell within the predicted fuzzy interval for a given day. Of note, in both years is that the fuzzy interval increases and decreases at different points throughout the years reflecting the certainty associated with the prediction, whereas, the EIV regression interval is constant and independent of the magni- tude of the predicted peak flow. Thus, during periods of high flow rate, the fuzzy interval expands to reflect the associated uncertainty with high flow predictions; and at lower flows, it reflects the opposite. In some lower flow cases show in Figure 3, the fuzzy interval is actually smaller than the crisp interval. While the majority of observations are captured within the in- tervals, the fuzzy interval is generally closer to the observations when the observations do not fall within the interval.

A plot of the observed versus predicted peak flow rate for the entire dataset are included in Figure 4. The figure shows that the fuzzy numbers (represented here as a black square corresponding to the values at $\mu=0$ ) and crisp numbers from both regression generally follow the 1:1 line. The fuzzy predicttions tend to expand for higher peak flow rates (representing the higher uncertainty associated with high peak flow). The flood event of 2005 can be seen clearly in the validation plot: the fuzzy intervals are closer to the $1: 1$ line compared to the crisp results for the flood level flows. Figure 5 plots the observed mean daily flow and daily peak flow for both the calibration and validation datasets. This figure clearly illustrates that the fuzzy intervals increase with the magnitude of peak flow rate, and thus, capture more of the uncertainty in the observations compared to the EIV regression method.

Figure 6 summarizes three performance metrics in order to compare the performance of the EIV and FLR for the $e$ $=20 \%$ proof-of-concept models (results for the other $e$ values are included in the Supporting Information). In general, performance decreases, for both methods, as the lags are increased. The model rankings (discussed below) show that in general the model performances decline from "very good" at a 1 day lag to "satisfactory" at a 7 day lag. Thus, this indicates that the optimum approach for this data-driven method is limited to short term predictions, between 1 and 3 days. In general, better performance is seen with the higher $e$ value.

For the Bow River at Banff, the average ranking for the validation datasets for the EIV and FLR models is "very good" for lags of 1 and 2 days for all $e$ values. The ranking decreases to "good" for a 3 day lag, and "satisfactory" for a 7 day lag for all $e$ values. Results for the calibration datasets

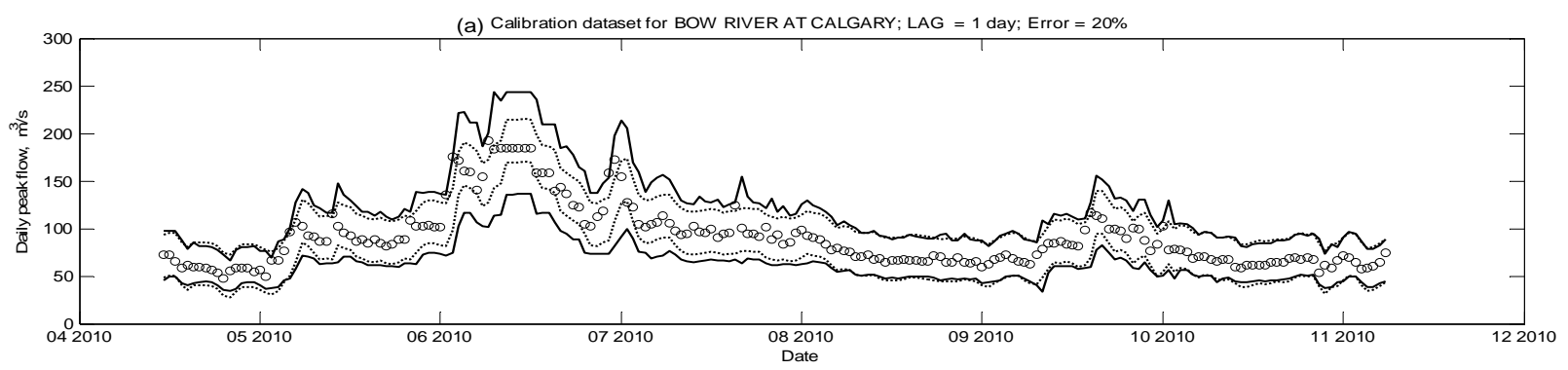

(b) Validation dataset for BOW RIVER AT CALGARY; LAG $=1$ day; Error $=20 \%$

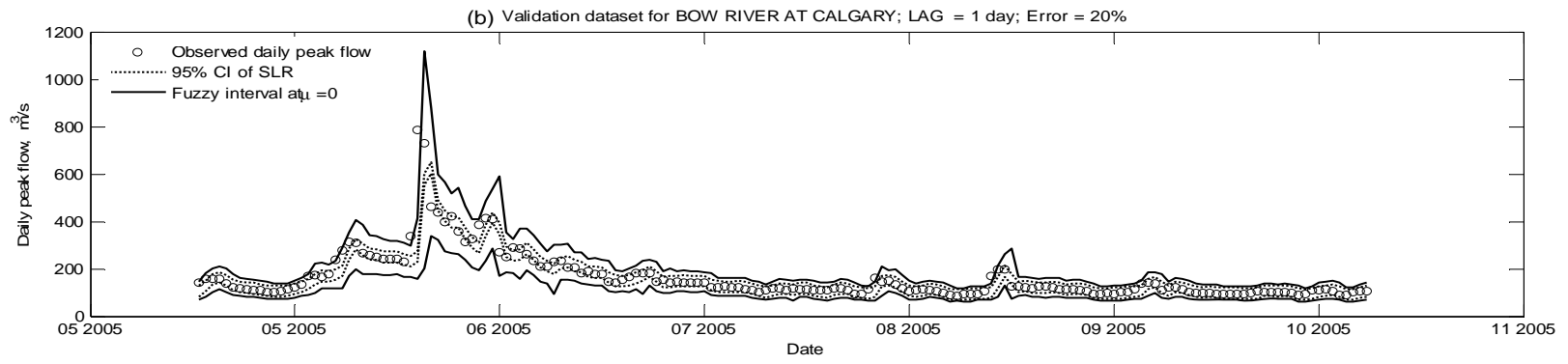

Figure 3. Results from the proof-of-concept models for a lag of 1 day, and $e$ of $20 \%$ : trend plots of predicted daily peak flow rate from the error-in-variables and fuzzy linear regression methods for (a) the calibration (shown for 2010 only), and (b) the validation dataset (shown for 2005 only) for the Bow River at Calgary. 

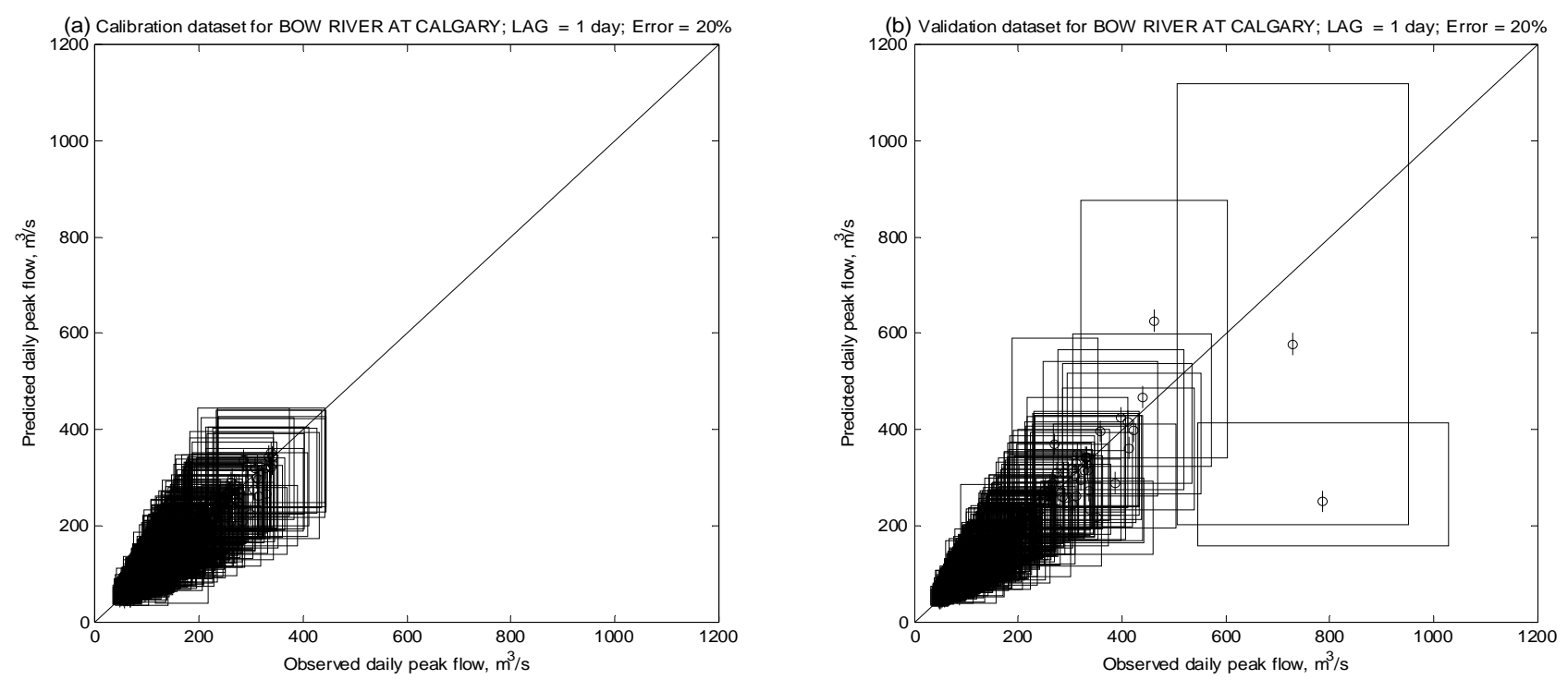

Figure 4. Results from the proof-of-concept models for a lag of 1 day, and $e$ of $20 \%$ : observed versus predicted peak flow rate plots for the error-in-variables (black circle with line) and fuzzy linear regression (black boxes) methods for (a) the calibration, and (b) the validation dataset for the Bow River at Calgary.
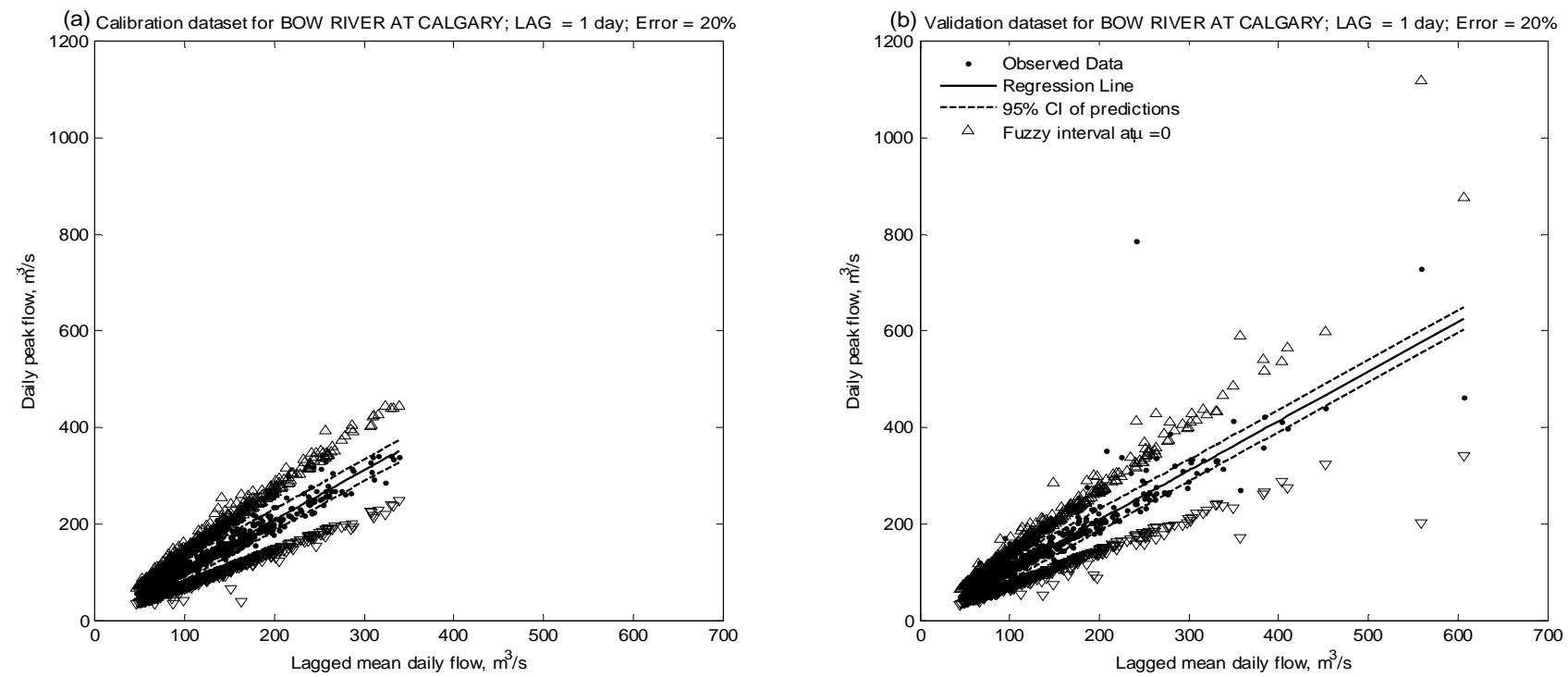

Figure 5. Results from the proof-of-concept models for a lag of 1 day, and $e$ of $20 \%$ : observed peak flow rate, the error-in-variables regression line, $95 \%$ confidence intervals, and fuzzy interval at $\mu=0$ for the (a) calibration and (b) validation dataset for Bow River at Calgary.

(not shown) are typically equal to or higher than the validation dataset. For the Bow River at Calgary, the average ranking for the validation dataset for the FLR model is "very good" for lags at 1 day, "good" for lags at 2 and 3 days, and "satisfactory" for a lag of 7 days. The EIV model has ranking of "very good" for lags of 1 and 2 days, and "good" and "satisfactory" for lags of 3 and 7 days, respectively, for the validation dataset. Again, calibration results (not shown) were either equal to or higher than the validation datasets. For the Elbow River at Bragg Creek, the average ranking for the FLR model is "unsatisfactory" for all validation cases, except for a lag of 1 day and an $e$ of $20 \%$ where it is classified as "satis- factory". The calibration dataset are ranked "satisfactory" or "good" for all cases. The validation dataset for the EIV model is ranked "satisfactory" (with $\mathrm{AR}=0.33$ ) for all four lags.

Between the sites, the Elbow River at Bragg Creek has noticeably lower performance than the other two sites. The Bragg Creek site has a much smaller drainage area than the other two sites, and a much larger range of annual peak flow rate $\left(15-307 \mathrm{~m}^{3} / \mathrm{s}\right)$. This suggests that this site experiences more flash flooding events than the other two sites, and perhaps this model structure is not the optimum for this site. An independent parameter other than $Q_{D}$ could improve model performance and be more suitable for this site. 


\subsubsection{Recursive Methods}

Figures 7 to 9 show results for recursive Model 5 for the Bow River at Calgary (Model 5 uses data from 2000 to 2004 for model construction and 2005 for validation). The trend plot in Figure 7 shows results from 2005, for a lag of 1 day, and $e$ of $20 \%$. These results again highlight the flexibility of the FLR approach: the predicted intervals increase and decrease as a function of the observed mean flow rate, and capture the majority of the observations. This is also highlighted in the results show in Figures 8 and 9. Note that in instances, the EIV results do not come close to the 1:1 line, but the FLR method (black squares) are closer to, or intersect, the 1:1 line. This means that for the same case, the FLR method can come closer to predicting the peak flow rate for a major flood event (2005) one day in advance, as compared to the EIV method.

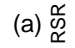

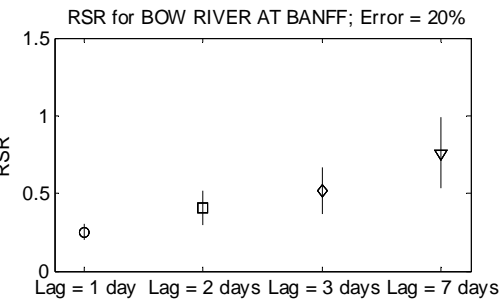

(b) $\underset{\sim}{\stackrel{0}{\sim}}$

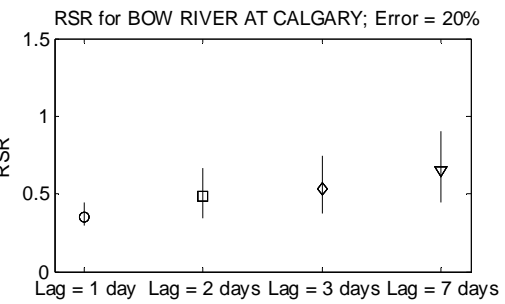

(c)

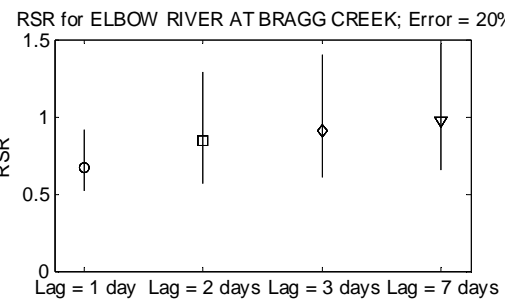

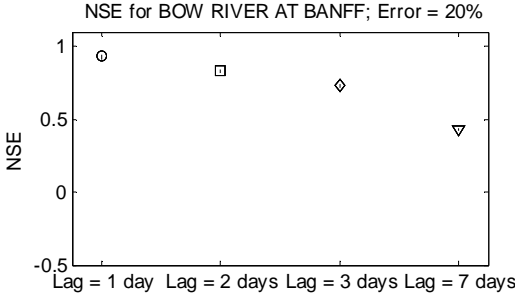
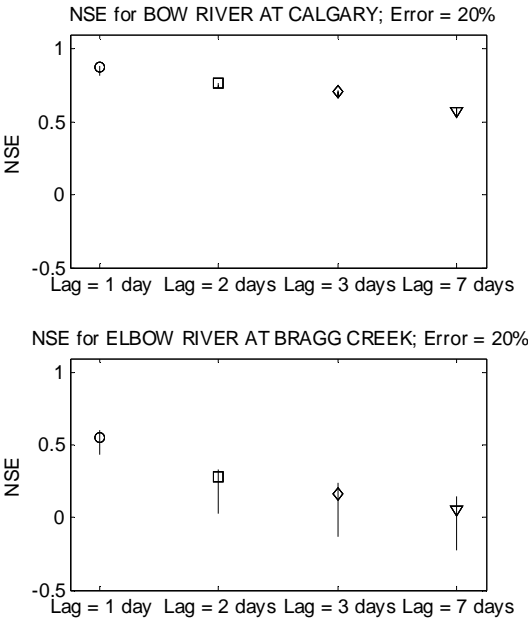
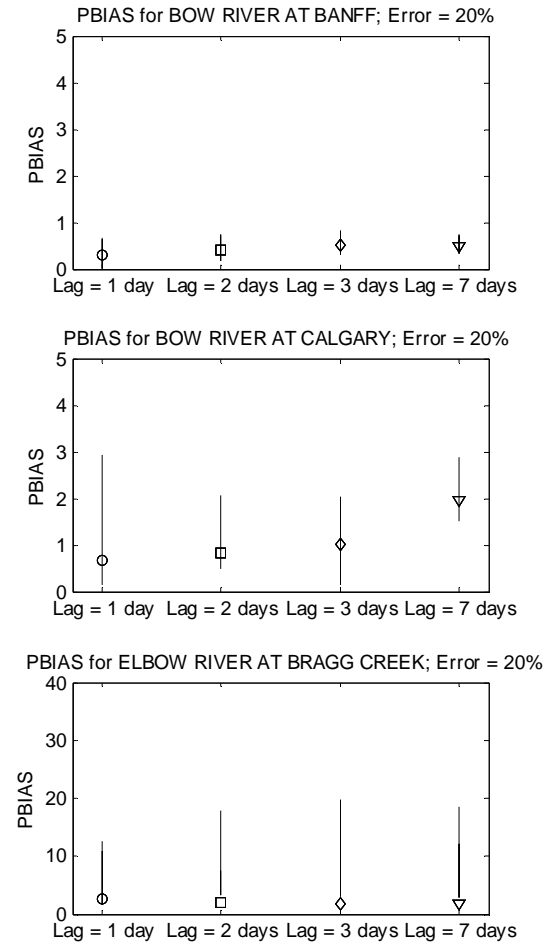

Figure 6. RSR, NSE and PBIAS values for the validation dataset for $e=20 \%$ proof-of-concept models: the markers (circle, square, rhombus, and triangle) represent results for different lags (1, 2, 3 and 7 days, respectively): Banff (a), Calgary (b) and Bragg Creek (c).

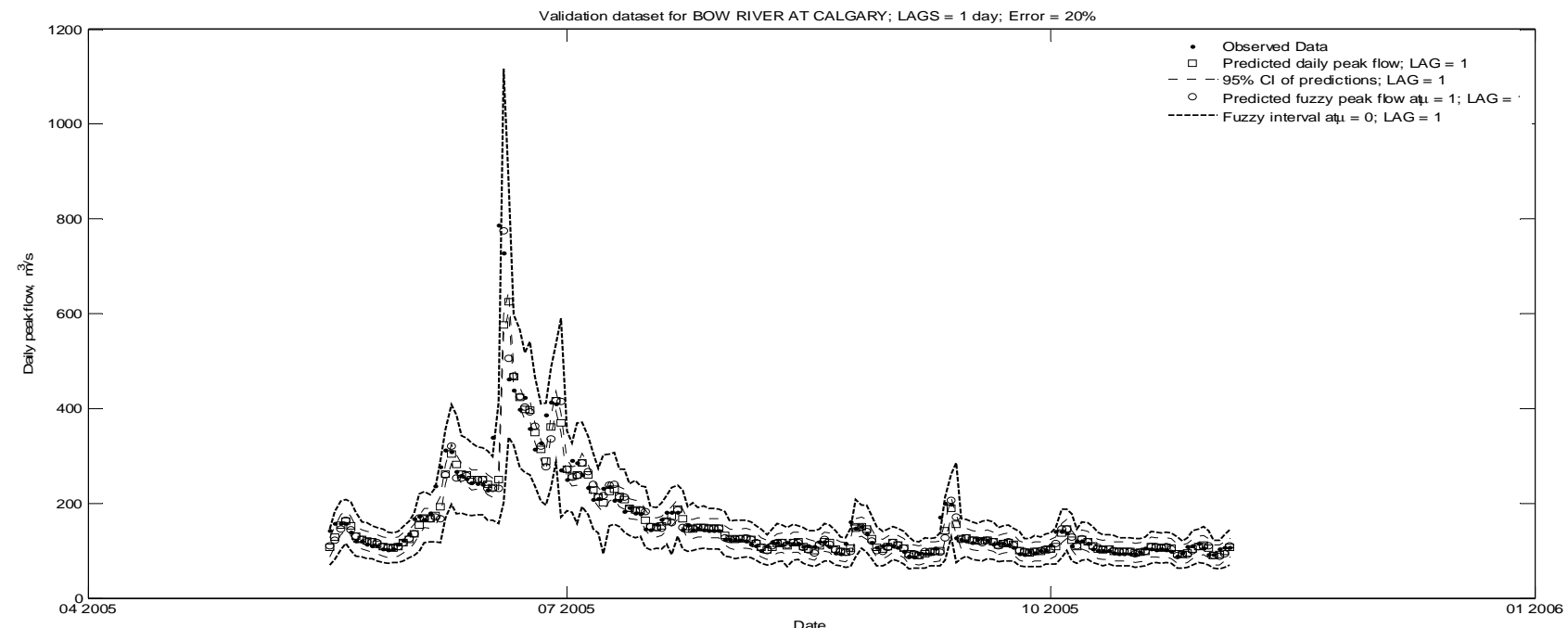

Figure 7. Results from the recursive model for a lag of 1 day, and $e$ of $20 \%$ : trend plots of predicted daily peak flow rate from the error-in-variables and fuzzy linear regression methods for the validation dataset (for 2005) for the Bow River at Calgary. 

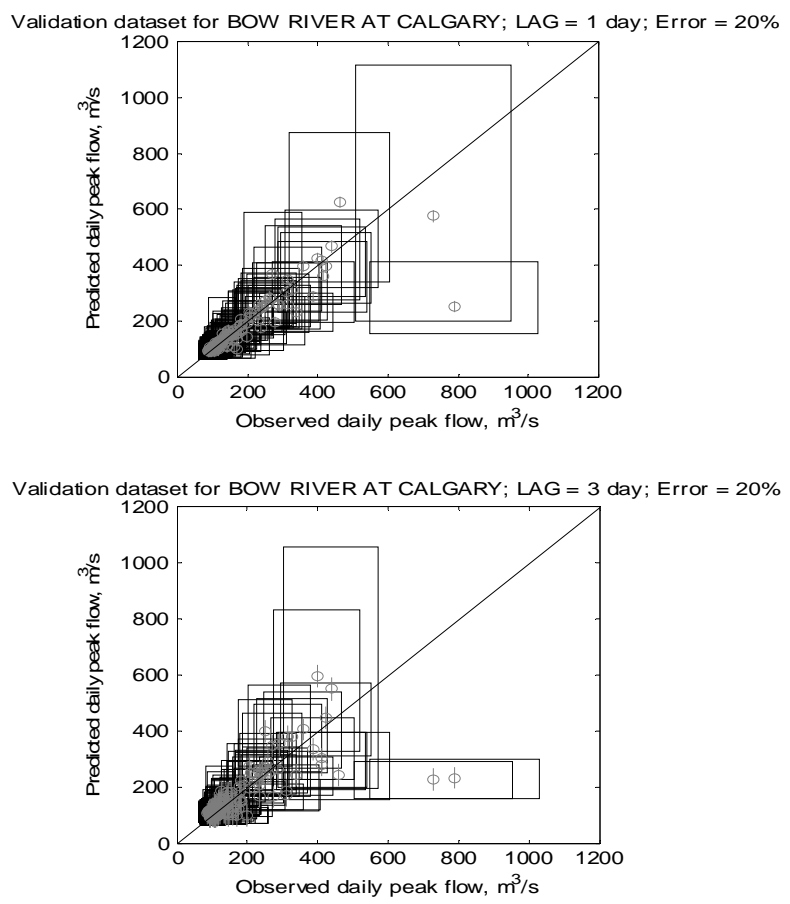
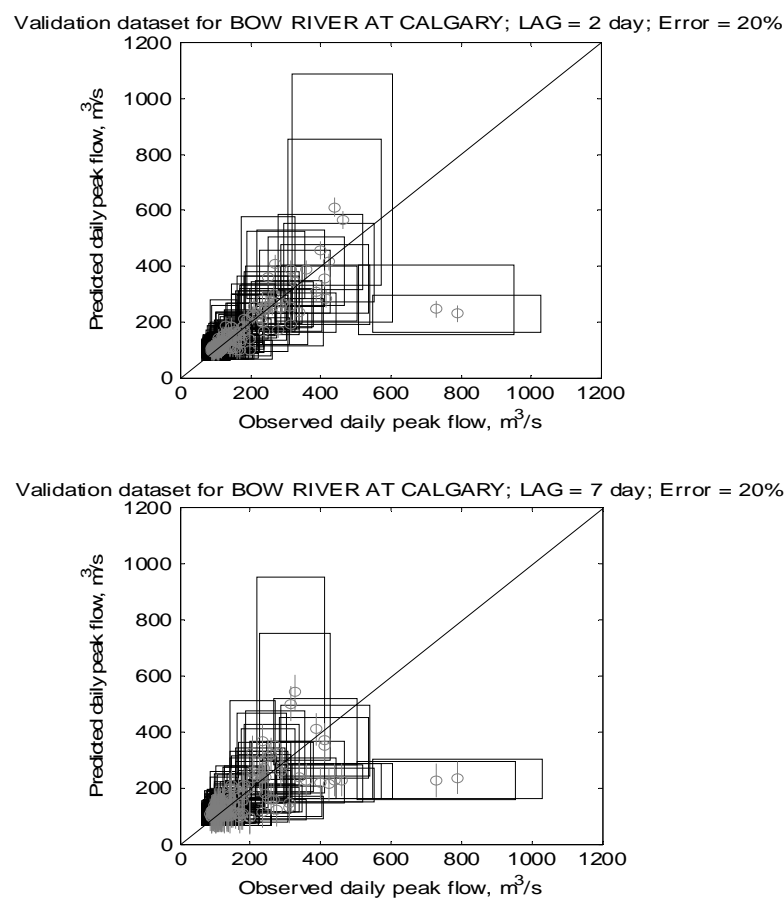

Figure 8. Results from the recursive models for all lags, and $e$ of $20 \%$ : observed versus predicted peak flow rate plots for the error-in-variables (grey lines) and fuzzy linear regression (black boxes) methods for the validation dataset (for year 2005 only) for the Bow River at Calgary.

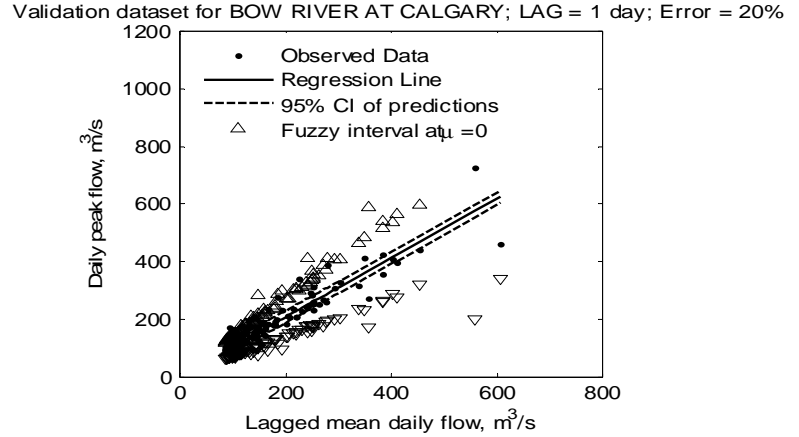

Validation dataset for BOW RIVER AT CALGARY; LAG $=3$ day; Error $=20 \%$

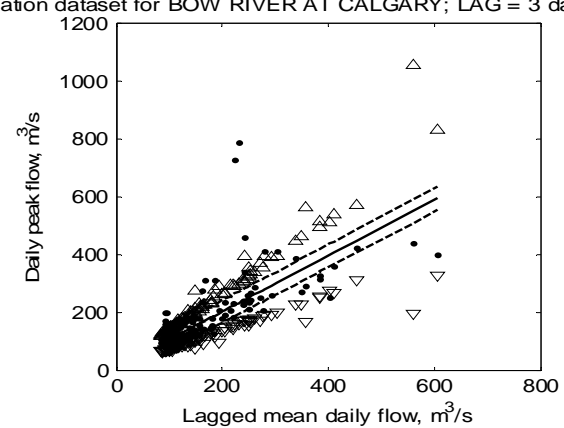

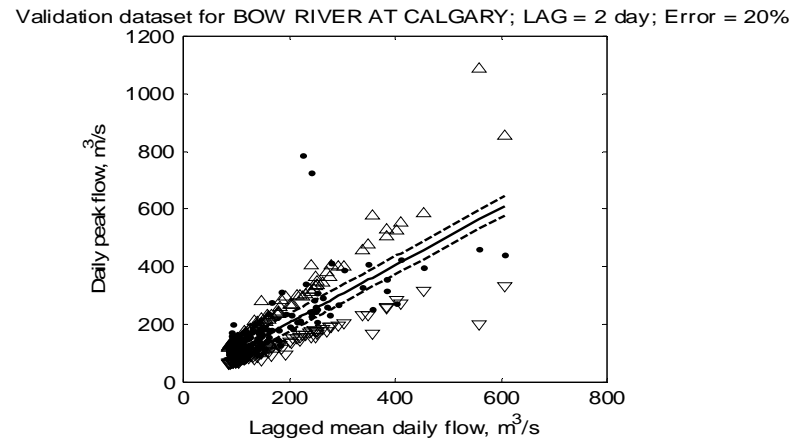

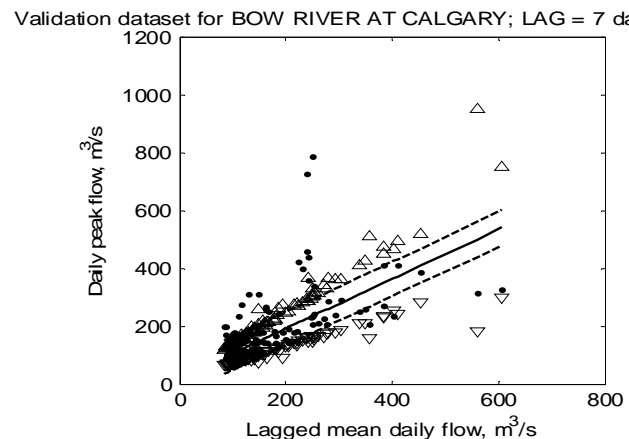

Figure 9. Results from the recursive models for all lags, and $e$ of 20\%: observed peak flow rate, the error-in-variables regression line, $95 \%$ confidence intervals, and fuzzy interval at $\mu=0$ for the validation dataset (for year 2005 only) for Bow River at Calgary.

Figure 10 shows plots of the three performance metrics used, for each model, for each site, for each lag, and for $e=$ $20 \%$. In general, the RSR plots show that the performance of all models, at all sites, does not change as the amount of data used is increased. This suggests that the issue of "over-learning" have been avoided in this case. The RSR performance 
(a)
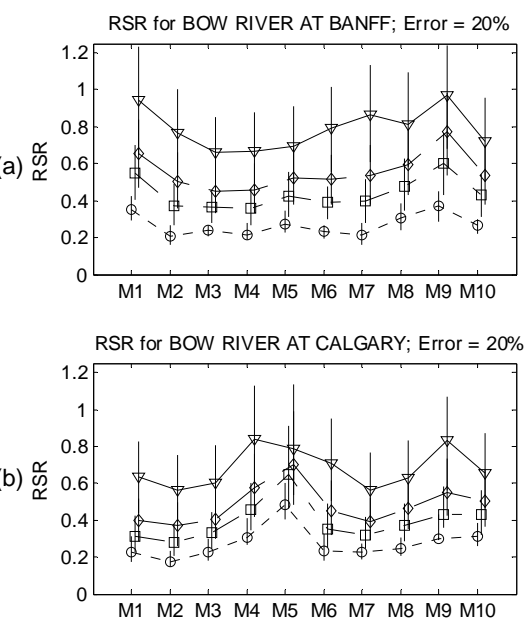

RSR for ELBOW RIVER AT BRAGG CREEK; Error $=20 \%$

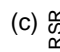

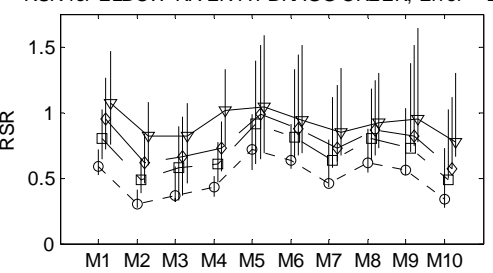

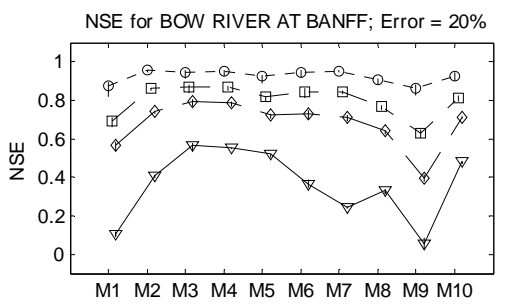
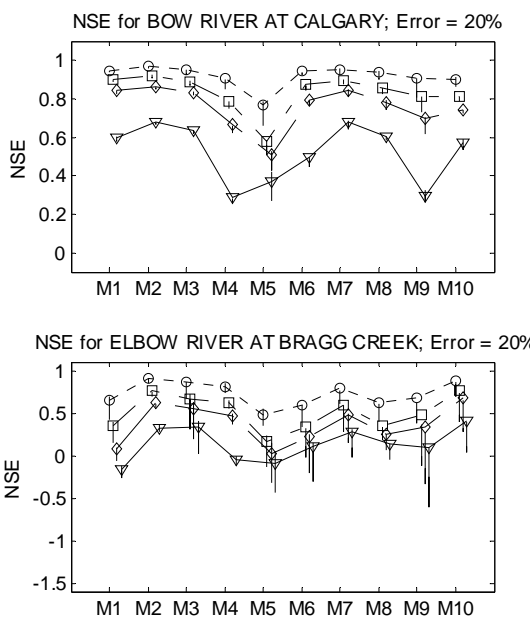
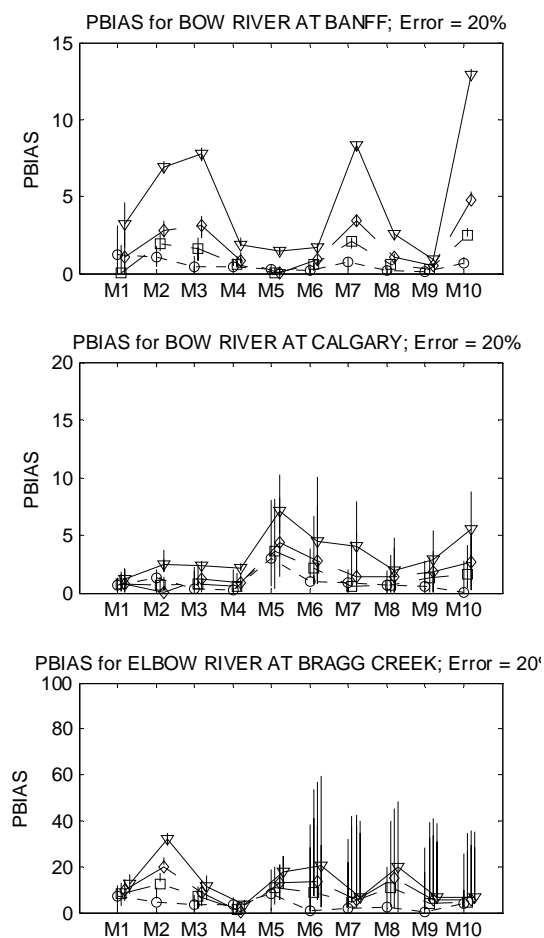

Figure 10. RSR, NSE and PBIASvalues for the validation dataset for all ten recursive models with $e=20 \%$ : the markers (circle, square, rhombus, and triangle) represent result for different lags (1, 2, 3 and 7 days, respectively), for each of the three sites: Banff (a), Calgary (b) and Bragg Creek (c).

decreases with increasing lags, and generally, a better performance is seen for the fuzzy system as the $e$ value increases. Better performances are generally seen at Banff and at Calgary than at Bragg Creek. The NSE values for Bragg Creek are much lower than those of the other two sites at lag 7; indicating the lack of a linear relationship. The improvement with increasing $e$ is more noticeable for Calgary and Bragg Creek than for Banff, where performance is high for all three $e$ cases. The results confirm that performance decreases as lag increases, and an improvement can be seen (especially for Calgary and Bragg Creek) as $e$ increases.

For the FLR validation case, for an $e$ of $20 \%$, the average ranking for Banff ranges from "very good" for all 10 models at 1 day lag, to a range between "good" and "very good" for a 2 day lag, "satisfactory" to "good" for a 3 day lag, and "satisfactory" for the 7 day lag (with one unsatisfactory case for Model 10). For Calgary, the average ranking for the FLR model was "very good" for both 1 and 2 day lags (with the exception of Model 5 for the two day lag which had a rating of "good"). The ranking was "satisfactory" to "very good" for the 3 day lag, and "satisfactory" to "good" for the 7 day lag. Lastly, for Bragg Creek, the average ranking for the FLR models was between "unsatisfactory" and "very good" for a 1 day lag, "unsatisfactory" and "good" for the 2 day lag, and "unsatisfactory" to "satisfactory" for the 3 and 7 day lags. Similar results were seen for the EIV case.

The last component of the model performance evaluation was calculating $D$. First, all days where the observed peak flow rate was higher than the calculated $Q_{P 2} \%$ flow rate were isolated. There were 30 occurrences of these high flows at Banff, 36 at Calgary, and 32 at Bragg Creek between 2000 and 2010 . Then, for each model (only recursive models with $e$ of $20 \%$ are considered for this analysis) the days when the observed flow did not fall within the predicted intervals for both EIV and FLR was isolated. The distance between the upper limit of the interval and the observed peak flow rate was then calculated, and the mean of these distances was summarized for each model for each site; these results are shown in Table 3.

This table shows that for days when the models entirely

Table 3. Distance Results for all Lags for an e $=20 \%$ for each Site

\begin{tabular}{|c|c|c|c|c|c|c|c|c|c|}
\hline \multicolumn{10}{|c|}{ Distance $\left(\mathrm{m}^{3} / \mathrm{s}\right)$} \\
\hline \multirow[t]{2}{*}{ Lag } & \multicolumn{3}{|l|}{ Banff } & \multicolumn{3}{|c|}{ Calgary } & \multicolumn{3}{|c|}{ Bragg Creek } \\
\hline & FLR & EIV & No. & FLR & EIV & No. & FLR & EIV & No. \\
\hline 1 day & 0 & 24 & 15 & 160 & 231 & 3 & 88 & 87 & 9 \\
\hline 2 days & 19 & 39 & 8 & 111 & 152 & 10 & 86 & 75 & 22 \\
\hline 3 days & 46 & 52 & 11 & 100 & 127 & 16 & 89 & 76 & 25 \\
\hline 7 days & 102 & 74 & 22 & 127 & 118 & 24 & 76 & 65 & 30 \\
\hline
\end{tabular}


under predict the observed peak flow rates, the FLR has a smaller distance between the highest point of the interval and the observation for a majority of cases. For example, in Banff the FLR has a significantly smaller distance (calculated using the two-sample Kolmogorov-Smirnov test at the 5\% level) for the 1 and 2 day lag cases than for EIV. For Calgary, the FLR performs substantially better than EIV for lags 1 to 3; however, these differences were not significant and were impacted by the low sample size. Lastly, for the Bragg Creek models, the EIV has a smaller distance than the FLR for all cases, but these were not found to be significantly different.

\subsection{Flood Risk Assessment}

Due to the importance of flood risk assessment for the City of Calgary in the wake of the June 2013 floods, the risk assessment reported here is only for the Calgary site using the recursive model with a 1 day lag and $e$ of $20 \%$ (only validation data was used for this analysis). A subset of the full dataset was taken to highlight the difference between the models. For each site, days when the observed flow was greater than the $Q_{P 2} \%$ was selected, reflecting high peak flow observations. The data is further filtered to include only the days when observed values are not captured within the EIV model interval, and when the EIV model under predicts the observations. A plot of the $95 \% \mathrm{CI}$ of the predictions, the corresponding observations, the fuzzy number, and the $Q_{P 2 \%}$ (the "Warning" flow") are plotted in Figure 11.

On each subplot, two probabilities calculated using the possibility to probability transformation are listed. The first value represents the probability that the predicted fuzzy peak flow will be higher than the $Q_{P 2 \%}$ flow, and the second represents the probability that the predicted fuzzy peak flow will be higher than the observed peak flow. These plots show that even when the EIV model's predicted peak flow rate does not capture the observed flow within its $95 \% \mathrm{CI}$, the fuzzy predicttions not only capture this high flow but can estimate the probability of that event. For example, in Calgary on 8 June 2005 with a one day lag, the EIV interval is between 241 and 282 $\mathrm{m}^{3} / \mathrm{s}$, whereas the observed peak flow for the day was 312 $\mathrm{m}^{3} / \mathrm{s}$. The fuzzy number meanwhile ranges between 170 and $355 \mathrm{~m}^{3} / \mathrm{s}$, and predicts the probability that the peak flow would be greater than $312 \mathrm{~m}^{3} / \mathrm{s}$ (what was observed) as $12 \%$. Based on this, a water resource manager in the municipality could issue a flood advisory a day before this high peak flow was seen.

The utility of the fuzzy number approach lies in its ability to calculate the probability of exceedance from its predictions. A water resource manager can provide a risk tolerance, e.g. if the probability that a predicted peak flow will be higher than $Q_{P 2 \%}$ is greater than 5\%, a "flood advisory" can be issued. Another tolerance for a more certain outcome, e.g. if the probability that a predicted peak flow will be higher than $Q_{P 2 \%}$ is greater than $50 \%$, a "flood warning" can be issued. In general, the fuzzy predictions are equal to, if not better than the EIV method, but in addition, fuzzy numbers can provide more meaningful information for flood mitigation.
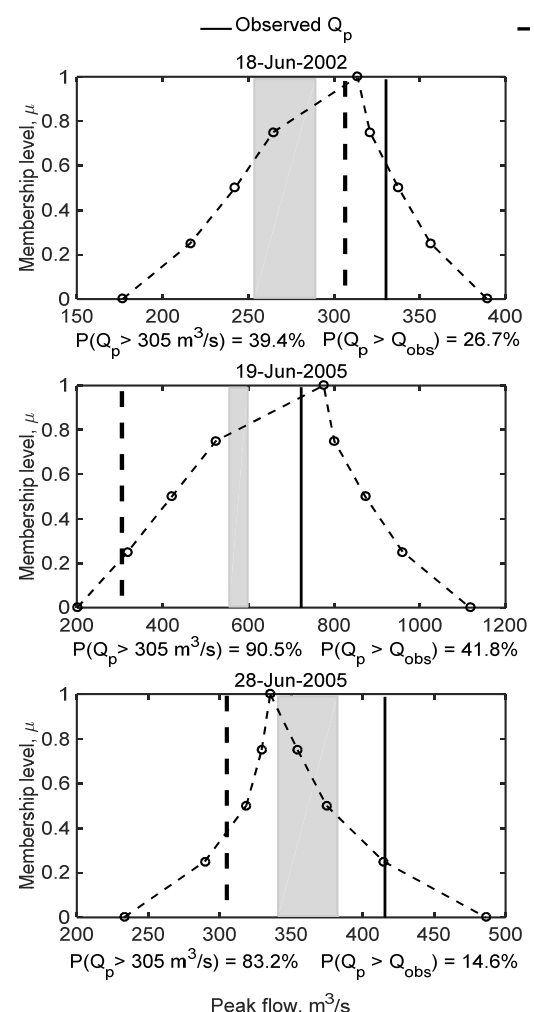
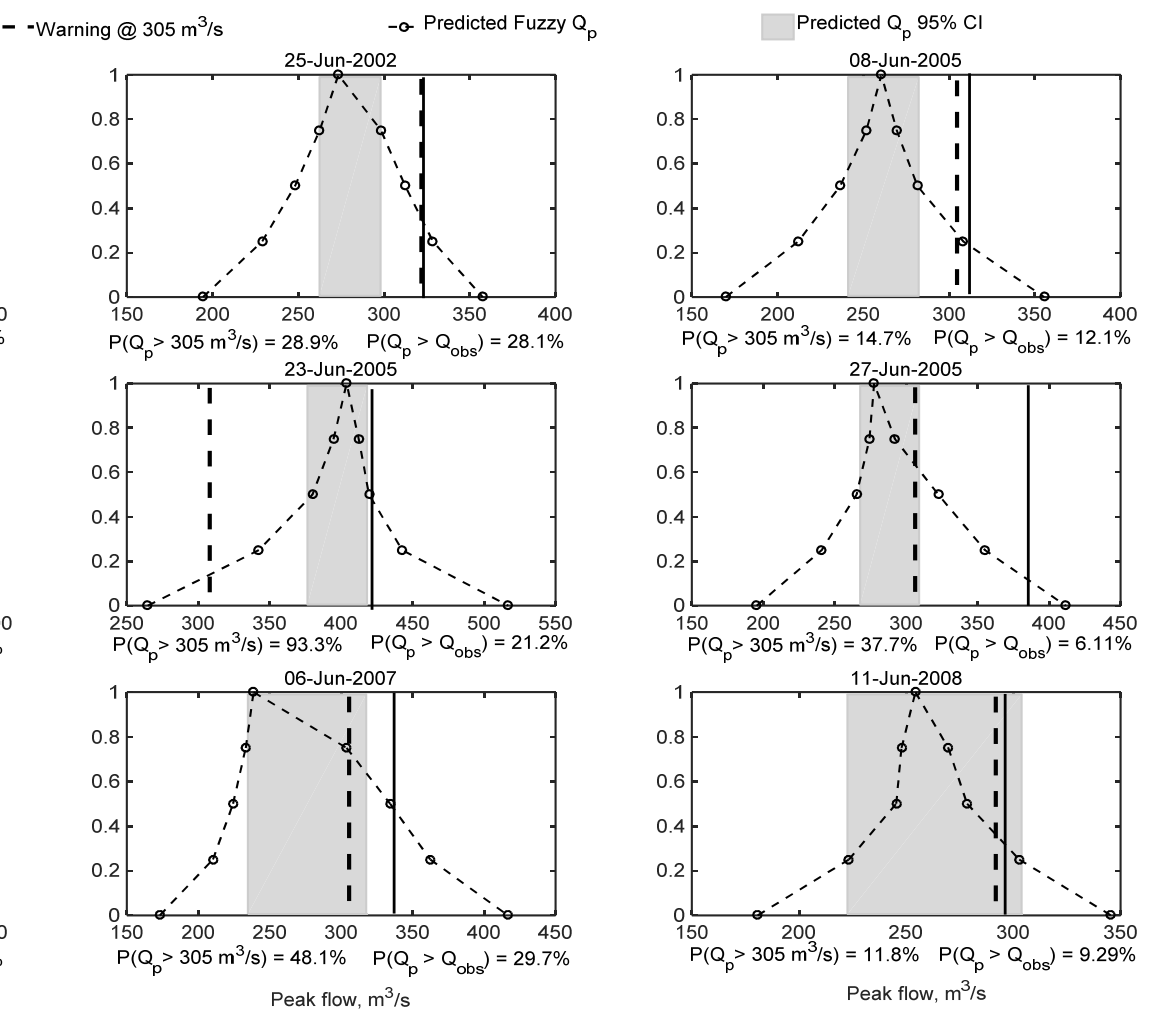

Peak flow, $\mathrm{m}^{3} / \mathrm{s}$

Figure 11. Possibility to probability transformations for high peak flow rate days $\left(>Q_{P 2 \%}\right)$, for Bow River at Calgary, with a lag of 1 day, and $e$ of $20 \%$. 


\subsection{Model Application: 2013 Flood Data}

An analysis using the developed model was conducted on an independent dataset: Model 10 (both EIV and FLR) for the 1 day lag and $e$ of $20 \%$ were used to predict the peak flow rate at Calgary in 2013. A similar analysis as for the previous years was conducted and is summarized in Figures 12 - 14 below.

As Figure 12 shows, the fuzzy interval encompasses the peak flow rate for the entire year except for the one day lea- ding up to the flood. This is highlighted in Figure 13, where the black boxes (representing fuzzy numbers) all cross the 1:1: line at all times, except for one occasion. However (discussed in detail below) during this particular day the fuzzy number is still able to predict the risk of high peak flow (i.e. $\left.P\left(x>Q_{P 2} \%\right)\right)$ whereas the EIV method does not warn of this risk. The RSR value for the FLR ranged between 0.50 and 0.72 , whereas the EIV had a value of 0.60 . The NSE values for FLR ranged between 0.48 and 0.76 , whereas the EIV had

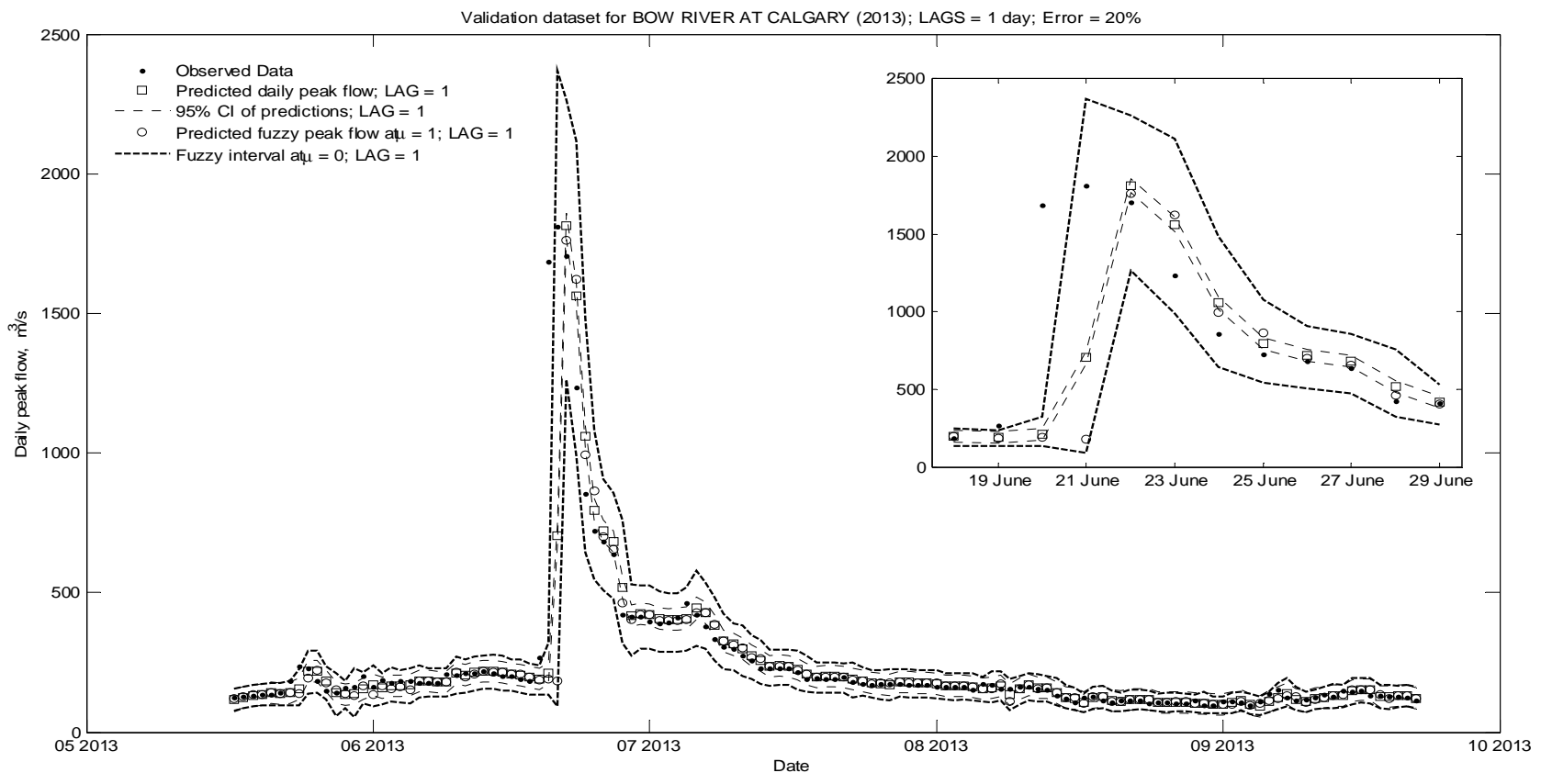

Figure 12. Results from the test case of 2013 for a lag of 1 day, and $e$ of $20 \%$ : trend plot of predicted daily peak flow rate from the error-in-variables and fuzzy linear regression methods for the Bow River at Calgary. The insert shows the days of interest in June 2013 when the highest flows were measured.
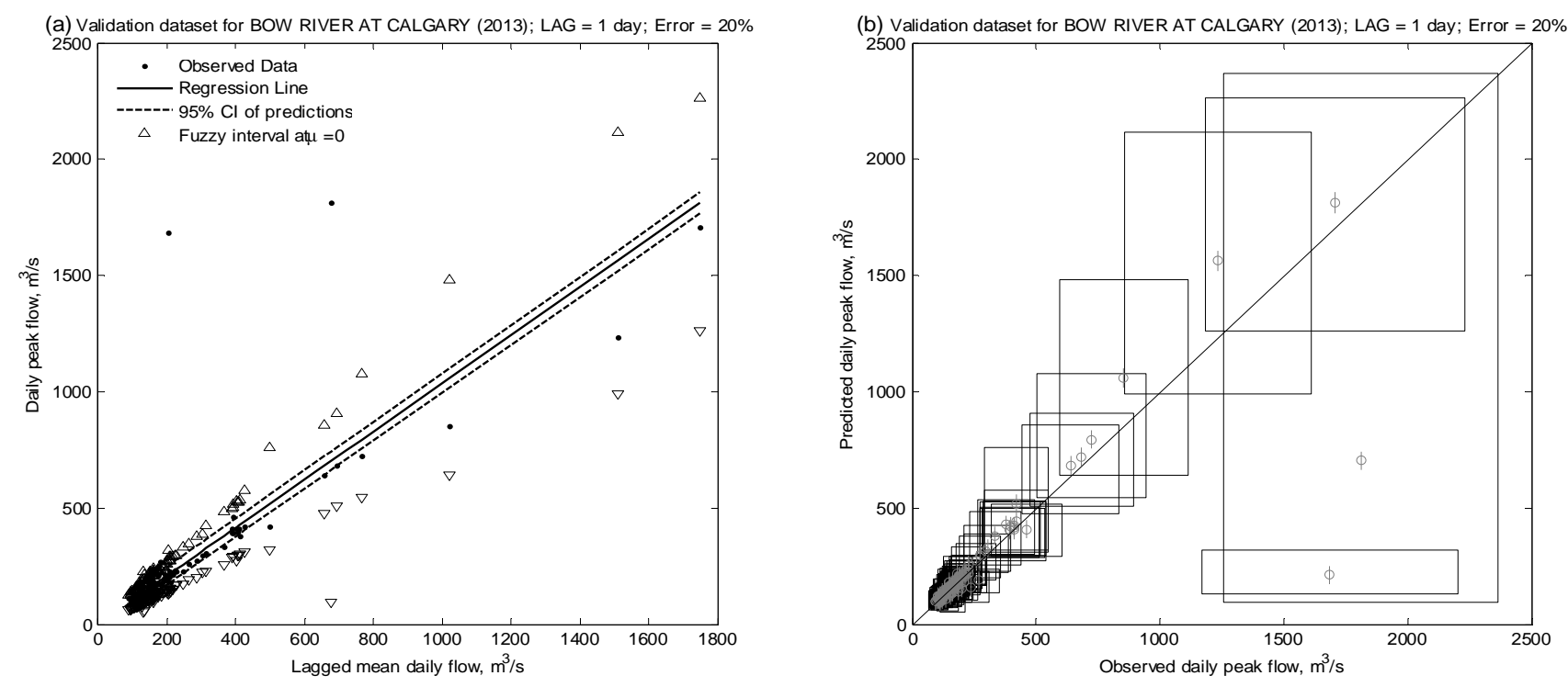

Figure 13. Results from the test case of 2013 for a lag of 1 day, and $e$ of 20\%: (left): observed versus predicted peak flow rate plots for the error-in-variables (grey lines) and fuzzy linear regression (black boxes) methods; and (right)observed peak flow rate, the error-in-variables regression line, $95 \%$ confidence intervals, and fuzzy interval at $\mu=0$ for the Bow River at Calgary. 
a value of 0.62 . Lastly, the PBIAS for FLR ranged between 1.7 and $9.2 \%$, whereas the EIV had a value of $5 \%$. For both models, the average ranking was "satisfactory", which is somewhat lower compared to the other 1 day, $20 \% e$ models for Calgary discussed earlier.

To focus on the flood event, a critical 12 day period from the $18^{\text {th }}$ to the $29^{\text {th }}$ of June, 2013 is plotted in Figure 12 as an insert. The figure clearly shows that the FLR method is more flexible and reactive to the flood event, by coming closer to the observed peak flow on the $20^{\text {th }}$ of June 2013 (unlike the EIV method) and capturing the peak flow rate on the $21^{\text {st }}$ of June 2013, which lies within the fuzzy interval. In fact, during this period, the EIV did not capture the observed peak flow within its $95 \%$ CI interval 9 out of the 12 days, whereas the FLR method only missed the observations on 3 out of 12 occasions.

Figure 14 shows the possibility to probability transformation for this 12 day period in 2013. It shows that on June $20^{\text {th }} 2013$, the fuzzy method still predicts a $\sim 4 \%$ chance that the observed peak flow will be greater than the warning level $\left(Q_{P 2 \%}\right)$ whereas the EIV interval is still under the threshold. Thus, even with an event that rises extremely rapidly (from $235 \mathrm{~m}^{3} / \mathrm{s}$ to $1600 \mathrm{~m}^{3} / \mathrm{s}$ in 18 hours on June 20 , 2013), the FLR method can predict a small risk of high peak flow a day in advance.

\section{Conclusions}

A fuzzy linear regression model was developed in this paper and tested against an error-in-variables implementation of ordinary least squares regression for flood prediction in a large river basin. A unique way of transforming a possibility to a probability for this particular type of data-driven modelling technique was also developed. In addition, the authors proposed a method to compare and evaluate fuzzy linear regression modelling to ordinary least squares regression modelling by modifying Moriasi et al.'s (2007) categories of model performance. In applying the models to the Bow River system in southern Alberta that experienced devastating floods in 2013, the research showed that the flood in June 2013 could not have been predicted with any confidence using current, conventional methods of probabilistic reasoning but could have been predicted a full day in advance, and potentially three days in advance for the City of Calgary using only observed real-time flow data gauged in the Bow River inside Calgary (WSC ID: 05BH004). This would provide enough advance warning to initiate flood response measures. The implementtation of this fuzzy linear regression would be amenable to reproduction as a web-passed app for use by forecasters or the public.

The proposed method can be further fine-tuned to improve model performance. For example, given the availability of sub-hourly flow rate data at some Environment Canada stations, it may be possible to use hourly, or perhaps 6-hour averaged data, rather than daily (24-hour averaged) data that was used in forming the models in this paper. Thus, the effect of a 1 time-unit lag would be less significant than in the current method, even though in the FLR method, the impact of the lag is compensated by the size of the fuzzy interval in most cases. However, it is important to note that by reducing the lead time
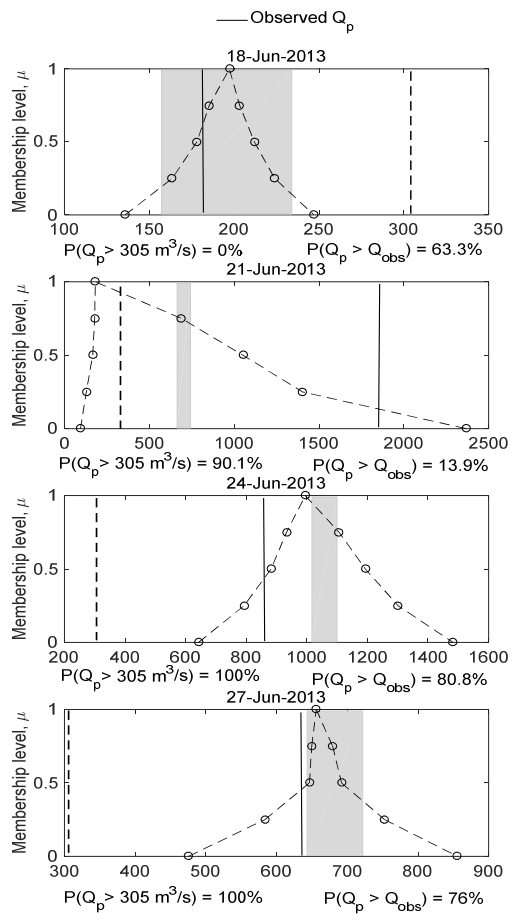

Peak flow, $\mathrm{m}^{3} / \mathrm{s}$
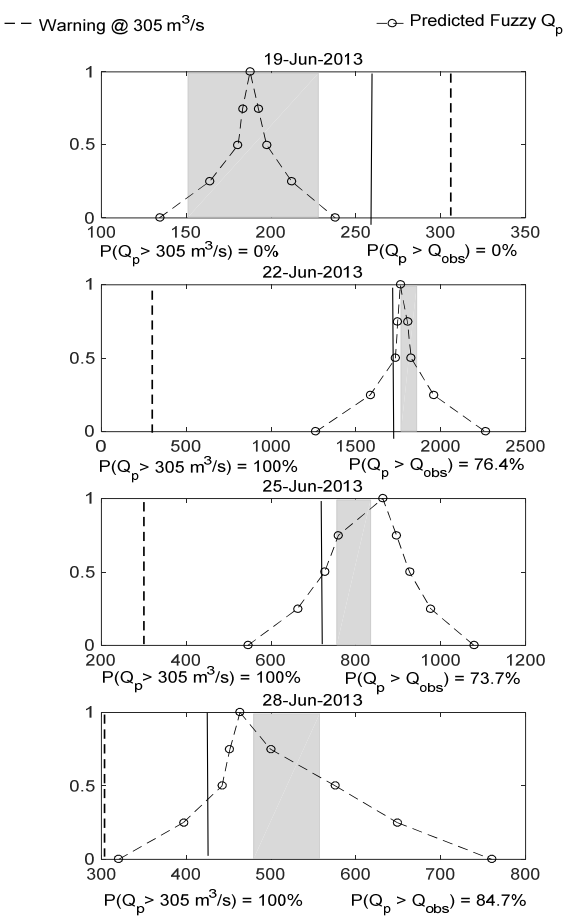

Peak flow, $\mathrm{m}^{3} / \mathrm{s}$
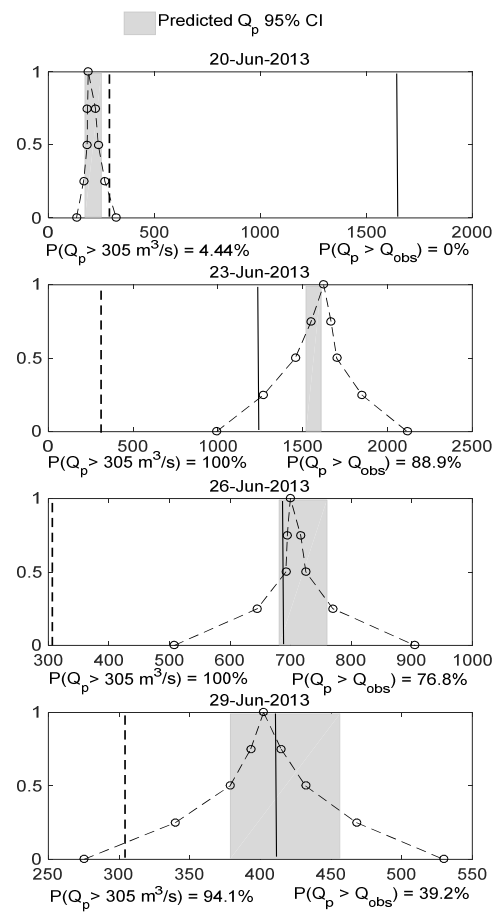

Peak flow, $\mathrm{m}^{3} / \mathrm{s}$

Figure 14. Possibility to probability transformations for high peak flow rate days $\left(>Q_{p 2} \%\right)$, for Bow River at Calgary in 2013 during the flood, with a lag of 1 day, and $e$ of $20 \%$. 
to sub-daily lags, that there will not be enough time to for water resource managers to implement flood defence systems, which is the primary objective of this risk-based peak flow prediction method.

Another method of improving performance could be by increasing the error value $e$ to up to $40 \%$ or $50 \%$ (from the maximum of $20 \%$ assumed in this paper). Increasing the window of the fuzzy number would improve model performance and capture more events within the fuzzy interval. It should be noted that even with such a high uncertainty band the proposed model has shown that it still reduces to a small interval when necessary (i.e. during low flow). Also, in this research it was assumed that the daily peak flow rate was a probabilistic parameter and converted to a fuzzy number for analysis; this is the most straight forward approach. However a number of propositions on converting a single flow measurement to a fuzzy number have been proposed and can be considered

Lastly, of the three sites considered, the models did not perform as well at the Elbow River at Bragg Creek site, as they did as the other two sites. Given this site's smaller drainage area and history of flash flooding, a different independent parameter might improve model performance, such as using lagged peak flow rate rather than lagged daily mean flow rate.

Acknowledgments. The authors would like to thank the Water Survey Division at Environment Canada for providing the data used for this research. The authors acknowledge NSERC, the Ministry of Higher Education (BC), and University of Victoria for funds supporting this research. Lastly, the authors are grateful for the helpful comments and suggestions by two anonymous reviewers that improved the quality and clarity of this manuscript.

Supporting Information. The supporting material containing Figures S1, S2, S3 and S4 are available at http://www.iseis.org/jei/Download/Supplement 201600345.pdf.

\section{References}

Abdalla, R., Elawad, Y., Chen, Z., Han, S.S., and Xia, R. (2014). A GIS-supported fuzzy-set approach for flood risk assessment. Can. Water Resourc. J., 39(1), 3-14. http://dx.doi.org/10.1080/07011784. 2014. 881058

Adamowski, J. and Sun, K. (2010). Development of a coupled wavelet transform and neural network method for flow forecasting of non-perennial rivers in semi-arid watersheds. J. Hydrol., 390(1), 85-91. http://dx.doi.org/10.1016/j.jhydrol.2010.06.033

Ahmad, S.S. and Simonovic, S.P. (2011). A three-dimensional fuzzy methodology for flood risk analysis. J. Flood Risk Manage., 4(1), 53-74. http://dx.doi.org/10.1111/j.1753-318X. 2011.01090.x

Ahmad, S.S. and Simonovic, S.P. (2013). Spatial and temporal analysis of urban flood risk assessment. Urban Water J., 10(1), 26-49. http://dx.doi.org/10.1080/1573062X.2012.690437

Ahmad, S.S. and Simonovic, S.P. (2015). System dynamics and hydrodynamic modelling approaches for spatial and temporal analysis of flood risk. Int. J. River Basin Manage., 13(4), 1-19. http:// dx.doi.org/10.1080/15715124.2015.1016954
Alberta Government (2014). Respecting Our Rivers: Alberta's Approach to Flood Mitigation. https://pabappsuat.alberta.ca/ albertacode/images/respecting-our-rivers.pdf.

Alvisi, S., and Franchini, M. (2011). Fuzzy neural networks for water level and discharge forecasting with uncertainty. Environ. Model. Software, 26(4), 523-537. http://dx.doi.org/10.1016/j.envsoft.2010. 10.016

Ardell, D. (2013a). Community Mitigation Elements: Alberta Flood Mapping, the Bow River Basin Council Quarterly Educational Forum, Calgary, AB. http://brbc.ab.ca/index.php/component/docman/ doc download/192-dave-ardell-flood-mapping.

Ardell, D. (2013b). Forecasting and Reservoir Operations, the Alberta Irrigation Projects Association 2013 Conference, Lethbridge, AB. http://www.aipa.ca/wp-content/uploads/2013/12/DavidArdell.pdf.

Baldassarre, G.D. (2012). Floods in a Changing Climate: Inundation Modelling, pp. 61-68. Cambridge University Press. Cambridge, UK.

Baldassarre, G.D. and Montanari, A. (2009). Uncertainty in river discharge observations: a quantitative analysis. Hydrol. Earth Syst. Sci., 13(6), 913-921. http://dx.doi.org/10.5194/hess-13- 913-2009.

Bárdossy, A. (1990). Note on fuzzy regression. Fuzzy Sets Syst., 37(1), 65-75. http://dx.doi.org/10.1016/0165-0114(90)90064- D

Bárdossy, A., Bogardi, I., and Duckstein, L. (1990). Fuzzy regression in hydrology. Water Resour. Res., 26(7), 1497-1508. http://dx. doi.org/10.1029/WR026i007p01497

Bogardi, I. and Duckstein, L. (2003). The Fuzzy Logic Paradigm of Risk Analysis. In Haimes, Y.Y., Moser, D.A., \& Stakhiv, E.Z. (Eds.), Risk-Based Decision making in Water Resources X, pp. 1222. http://dx.doi.org/10.1061/40694(2003)2

BRBC (2010a). Profile of the Bow River Basin: Hydrology. http:// wsow.brbc.ab.ca/index.php?option $=$ com_content\&view $=$ article\&i $\mathrm{d}=259$ \&Itemid $=83$.

BRBC (2010b). Profile of the Bow River Basin. http://wsow.brbc. ab. $\mathrm{ca} /$ index.php?option $=\mathrm{com} \_$content\&view $=$article $\& \mathrm{id}=81 \&$ Itemid $=$ 83 .

BRBC (2010c). Elbow River: History and Overview. http://wsow.brbc.ab.ca/index.php?option $=$ com_content\&view $=$ article $\&$ id $=160 \& I$ temid $=122$

Campolo, M., Soldati, A., and Andreussi, P. (1999). Forecasting river flow rate during low-flow periods using neural networks. Water Resour. Res., 35(11), 3547-3552. http://dx.doi.org/10.10 29/1999 WR900205

Chang, Y.H.O. and Ayyub, B.M. (2001). Fuzzy regression methods-a comparative assessment. Fuzzy sets syst., 119(2), 187- 203. http://dx.doi.org/10.1016/S0165-0114(99)00091-3

City of Calgary (2014). Calgary's Flood Resilient Future, the Expert Management Panel on Flood River Mitigation, PFC- 2014-0512. Calgary, Alberta. pp. 61.

Corani, G. and Guariso, G. (2005). Coupling fuzzy modeling and neural networks for river flood prediction. IEEE Trans. Syst. Man Cybern. C. Appl. Rev., 35(3), 382-390. http://dx.doi.org/10.1109/ TSMCC.2004.843229

Cox, B.A. (2003). A review of currently available in-stream waterquality models and their applicability for simulating dis- solved oxygen in lowland rivers. Sci. Total Environ., 314-316, 335-337. http://dx.doi.org/10.1016/S0048-9697(03)00063-9

Dubois, D. and Prade, H. (1997). Bayesian conditioning in possibility theory. Fuzzy Sets Syst., 92(2), 223-240. http://dx.doi. org/10. 1016/S0165-0114(97)00172-3

Dubois, D., Foulloy, L., Mauris, G., and Prade, H. (2004). Probability-possibility transformations, triangular fuzzy sets, and probabilistic inequalities. Reliable comput., 10(4), 273-297. http://dx. doi. org/10.1023/B:REOM.0000032115.22510.b5 
Dubois, D., Prade, H., and Sandri, S. (1993). On possibility/probability transformations. In Lowen, R. \& Roubens, M. (Eds.), Fuzzy Logic, pp. 103-112. Kluwer Academic Publishers, Dordrecht, Netherlands. http://dx.doi.org/10.1007/978-94-011-20 14-2 10

Duncan, A.P., Chen, A.S., Keedwell, E.C., Djordjevic, S., and Savic, D.A. (2011). Urban flood prediction in real-time from weather radar and rainfall data using artificial neural networks. In Weather Radar and Hydrology International Symposium, IAHS Red Book series no. 351, Exeter, UK. http://hdl.handle. net/10871/18406

Environment Canada (2005). Top Ten Weather Stories: 2005. http:// www.ec.gc.ca/meteo-weather/default.asp?lang $=$ En\&n=A4DD5AB 5-1.

Environment Canada (2013). Alberta's Flood of Floods on Canada's Top Ten Weather Stories for 2013. http://ec.gc.ca/me teo-weather/ default.asp?lang $=$ En\&n=5BA5EAFC-1\&offset $=2 \&$ toc $=$ show .

Environment Canada (2014). Wateroffice: Hydrometric Station Meta Data. https://wateroffice.ec.gc.ca/station_metadata/statio nList_e. html.

Fuller, W.A. (1987). Measurement error models, John Wiley \& Sons, New York, NY, USA.

Garen, D. (1992). Improved techniques in regression-based streamflow volume forecasting. J. Water Resour. Plann. Manage., 118(6), 654-670. http://dx.doi.org/10.1061/(ASCE)0733-9496 (19 92)118:6(654)

Guyonnet, D., Bourgine, B., Dubois, D., Fargier, H., Come, B., and Chiles, J.P. (2003). Hybrid approach for addressing uncer- tainty in risk assessments. J. Environ. Eng., 129(1), 68-78. http://dx.doi.org/ 10.1061/(ASCE)0733-9372(2003)129:1(68)

Hamilton, A.S. and Moore, R.D. (2012). Quantifying uncertainty in streamflow records. Can. Water Resour. J., 37(1), 3-21. http://dx. doi. org/10.4296/cwrj3701865

Harmel, R.D. and Smith, P.K. (2007). Consideration of measurement uncertainty in the evaluation of goodness-of-fit in hydrologic and water quality modeling. J. Hydrol., 337(3), 326-336. http://dx.doi. org/10.1016/j.jhydrol.2007.01.043

Huang, Y., Chen, X., Li, Y.P., Huang, G.H., and Liu, T. (2010). A fuzzy-based simulation method for modelling hydrological processes under uncertainty. Hydrol. Process., 24(25), 3718- 3732. http://dx. doi.org/10.1002/hyp.7790

Kahraman, C., Beşkese, A., and Bozbura, F.T. (2006). Fuzzy regression approaches and applications. In Kahraman, C. (Ed.), Fuzzy Applications in Industrial Engineering, pp. 589-615, Springer Berlin Heidelberg, Berlin, Germany. http://dx.doi.org/10.1007/3-540$33517-X 24$

Khan, U.T. (2014) Extreme event prediction and uncertainty analysis in the Bow River: A data-driven approach using fuzzy numbers, the 2014 CWRA-AB Annual Branch Conference, Calgary, AB, Canada. http://www.cwra-ab-events.org/Presentations/2014/S12-Khan.pdf.

Khan, U.T. and Valeo, C. (2014). Peak flow prediction using fuzzy linear regression: Case study of the Bow River, Proceedings of the International Conference on Marine and Freshwater Environments, St. Johns, NFLD.

Khan, U. T. and Valeo, C. (2015). A new fuzzy linear regression approach for dissolved oxygen prediction. Hydrol. Sci. J., 60 (6), 1096-1119. http://dx.doi.org/10.1080/02626667.2014.9005 58

Khan, U.T., Valeo, C., and He, J. (2013). Non-linear fuzzy-set based uncertainty propagation for improved DO prediction using multiplelinear regression. Stochastic Environ. Res. Risk Assess., 27(3), 599-616. http://dx.doi.org/10.1007/s00477-012- 0626-5

Kim, K.J., Moskowitz, H., and Koksalan, M. (1996). Fuzzy versus statistical linear regression. Eur. J. Oper. Res., 92(2), 417-434. http://dx.doi.org/10.1016/0377-2217(94)00352-1

Krueger, T., Freer, J., Quinton, J.N., Macleod, C.J., Bilotta, G.S.,
Brazier, R.E., Butler, P., and Haygarth, P.M. (2010). Ensemble evaluation of hydrological model hypotheses. Water Resour. Res., 46(7), W07516. http://dx.doi.org/10.1029/2009WR007845

Li, W., Zhang, H.T., Zhu, Y., Liang, Z.W., He, B., Hashmi, M.Z., Chen, Z.L., and Wang, Y.S. (2015a). Spatiotemporal classification analysis of long-term environmental monitoring data in the northern part of Lake Taihu, China by using a self-organiz- ing map. J. Enviro. Inf., 26(1), 71-79. http://dx.doi.org/10.3808/jei.20 1500297

Li, Z., Huang, G.H., Fan, Y.R., and Xu, J.L. (2015b). Hydrologic risk analysis for nonstationary streamflow records under un- certainty. J. Environ. Inf., 26(1), 41-51. http://dx.doi.org/10.38 08/jei.201500 321

Li, Z., Huang, G.H., Han, J.C., Wang, X.Q., Fan, Y.R., Cheng, G.H., Zhang, H., and Huang, W. (2015c). Development of a stepwiseclustered hydrological inference model. J. Hydrol. Eng., 20(10), 04015008. http://dx.doi.org/10.1061/(ASCE)HE.1943-5584.00011 65

Lohani, A.K., Goel, N.K., and Bhatia, K.K.S. (2014). Improving real time flood forecasting using fuzzy inference system. J. Hydrol., 509, 25-41. http://dx.doi.org/10.1016/j.jhydrol.2013. 11.021

Maddala, G.S. (1988). Introduction to econometrics (1st Ed.), Macmillan Publishing Company, New York, NY, USA.

Mauris, G. (2013). A review of relationships between possibility and probability representations of uncertainty in measurement. IEEE Trans. Instrum. Meas., 62(3), 622-632. http://dx.doi.org/ 10.1109/ TIM.2012.2218057.

McMillan, H., Krueger, T., and Freer, J. (2012). Benchmarking observational uncertainties for hydrology: rainfall, river dis- charge and water quality. Hydrol. Process., 26(26), 4078-4111. http://dx.doi. org/ 10.1002/hyp.9384.

Montgomery, D.C., Peck, E.A., and Vining, G.G. (2006). Introduction to Linear Regression Analysis. (4th Ed.), John Wiley \& Sons Inc. Hoboken, NY, USA.

Moriasi, D.N., Arnold, J.G., van Liew, M.W., Binger, R.L., Harmel, R.D., and Veith, T.L. (2007). Model evaluation guide- lines for systematic quantification of accuracy of watershed simulations. Trans. Am. Soc. Agric. Biol. Eng., 50(3), 885-900. http://dx.doi. org/ 10.13031/2013.23153

Nash, J.E. and Sutcliffe, J.V. (1970). River flow forecasting through conceptual models: Part I. A discussion of principles. J. Hydrol., 10(3), 282-290. http://dx.doi.org/10.1016/0022-169 4(70)90255-6

Nguyen, P.K.T. and Chua, L.H.C. (2012). The data-driven approach as an operational real-time flood forecasting model. Hydrol. Process., 26(19), 2878-2893. http://dx.doi.org/10.100 2/hyp.8347

Nourani, V., Khanghah, T.R., and Baghanam, A.H. (2015). Application of entropy concept for input selection of Wavelet-ANN based rainfall-runoff modeling. J. Environ. Inf., 26(1), 52-70. http://dx.doi.org/10.3808/jei.201500309

Oussalah, M. (2000). On the probability/possibility transforma- tions: A comparative analysis. Int. J. Gen. Syst., 29(5), 671- 718. http:// dx.doi.org/10.1080/03081070008960969

Ozbek, M.M. and Pinder, G.F. (2006). Non-probabilistic uncer- tainty in subsurface hydrology and its applications: An over- view. Water, Air, Soil Pollut. Focus, 6(1-2), 35-46. http://dx.doi.org/10.1007/s 11267-005-9011-4

Papa, F., Biancamaria, S., Lion, C., and Rossow, W.B. (2012). Uncertainties in mean river discharge estimates associated with satellite altimeter temporal sampling intervals: A case study for the annual peak flow in the context of the future SWOT hydrology mission. IEEE Geosci. Remote Sens. Lett., 9(4), 569-573. http://dx.doi.org/ 10.1109/LGRS.2011.2174958

Pappenberger, F., Matgen, P., Beven, K.J., Henry, J.B., and Pfister, L. (2006). Influence of uncertain boundary conditions and model 
structure on flood inundation predictions. Adv. Water Resour., 29(10), 1430-1449. http://dx.doi.org/10.1016/j. advwatres.2005.11. 012

Peters, G. (1994). Fuzzy linear regression with fuzzy intervals. Fuzzy Sets Syst., 63(1), 45-55. http://dx.doi.org/10.1016/0165- 0114(94) 90144-9

Robinson, K., Valeo, C., Ryan, M.C., Chu, A., and Iwanyshyn, M. (2009). Modelling aquatic vegetation and dissolved oxygen after a flood event in the Bow River Alberta, Canada. Can. J. Civ. Eng., 36(3), 492-503. http://dx.doi.org/10.1139/L08-126

Savic, D.A. and Pedrycz, W. (1991). Evaluation of fuzzy linear regression models. Fuzzy sets syst., 39(1), 51-63. http://dx.doi. org/10.1016/0165-0114(91)90065-X

Schilling, K.E. and Walter, C.F. (2005). Estimation of stream- flow, base flow, and nitrate-nitrogen loads in Iowa using mul- tiple linear regression models. J. Am. Water Resour. Assoc., 41(6), 13 33-1346. http://dx.doi.org/10.1111/j.1752-1688.2005. tb03803.x

Shen, Y., Chen, L., and Liao, Q. (2015). Effect of rainfall measurement errors on nonpoint-source pollution model uncertain- ty. J. Environ. Inf., 26(1), 14-26. http://dx.doi.org/10.3808/jei. 201400 271

Shrestha, R.R. and Simonovic, S.P. (2010). Fuzzy set theory based methodology for the analysis of measurement uncer- tainties in river discharge and stage. Can. J. Civ. Eng., 37(3), 429-440. http:// dx. doi.org/10.1139/L09-151

Solomantine, D.P. and Ostfeld, A. (2008). Data-driven modelling: some past experiences and new approaches. J. Hydroinf., 10 (1), 3-22. http://dx.doi.org/10.2166/hydro.2008.015

Valeo, C., Xiang, Z., Bouchart, F.J.C., Yeung, P., and Ryan, M.C. (2007). Climate change impacts in the Elbow River Watershed. Can. Water Resour. J., 32(4), 285-302. http://dx.doi.org/10.4296/ cwrj3204285

Veiga, V.B., Hassan, Q.K., and He, J. (2014). Development of flow Forecasting models in the Bow River at Calgary, Alberta, Canada. Water, 7(1), 99-115. http://dx.doi.org/10.3390/w7010099

Vrugt, J.A., Diks, C.G., Gupta, H.V., Bouten, W., and Verstraten, J.M. (2005). Improved treatment of uncertainty in hydrologic modeling: Combining the strengths of global optimization and data assimilation. Water Resour. Res., 41(1), W01017. http:// dx.doi.org/10.10 29/2004WR003059

Walford, C. (2014). Flood forecasting methodology in Alberta, Proceedings from the Workshop on Extreme Weather and Hydrology-Lessons Learned from the Western Canadian Floods of 2013 and Others, Canmore, AB. http://www.ccrnetwork.ca/science-programme/workshops/workshop-on-extreme-weather-and-hydrolog/ presentations/index.php.

Wang, S. and Huang, G.H. (2013). A two-stage mixed-integer fuzzy programming with interval-valued membership functions approach for flood-diversion planning. J. Environ. Manage., 117, 208- 218. http://dx.doi.org/10.1016/j.jenvman. 2012.12.037

Wang, S., Huang, G.H., and Baetz, B.W. (2014). An inexact probabilistic-possibilistic optimization framework for flood management in a hybrid uncertain environment. IEEE Trans. Fuzzy Syst., 23(4), 897-908. http://dx.doi.org/10.1109/TFUZZ.2014.233 3094

Westerberg, I., Guerrero, J.L., Seibert, J., Beven, K.J., and Halldin, S. (2011). Stage-discharge uncertainty derived with a non-stationary rating curve in the Choluteca River, Honduras. Hydrol. Process., 25(4), 603-613. http://dx.doi.org/10.1002/ hyp.7848

Wijesekara, G.N., Gupta, A., Valeo, C., Hasbani, J.G., Qiao, Y., Delaney, P., and Marceau, D.J. (2012). Assessing the impact of future land-use changes on hydrological processes in the Elbow River watershed in southern Alberta, Canada. J. hydrol., 412, 220232. http://dx.doi.org/10.1016/j.jhydrol.2011.04.018

Wittink, D.R. (1988). The application of regression analysis, Allan \& Bacon Inc. Needam Heights, MA, USA.

Yang, Y., Zhang, C.T., Zhang, R.X., and Christakos, G. (2015). Improving environmental prediction by assimilating auxiliary information. J. Environ. Inf., 26(2), 91-105. http://dx.doi.org/ 10.38 08/jei.201500316

Zadeh, L.A. (1965). Fuzzy sets. Inf. control, 8(3), 338-353. http://dx. doi.org/10.1016/S0019-9958(65)90241-X

Zadeh, L.A. (1978). Fuzzy sets as a basis for a theory of possi- bility. Fuzzy sets syst., 1(1), 3-28. http://dx.doi.org/10.1016/01 65-0114 (78)90029-5

Zealand, C.M., Burn, D.H., and Simonovic, S.P. (1999). Short term streamflow forecasting using artificial neural networks. J. hydrol., 214(1), 32-48. http://dx.doi.org/10.1016/S0022-1694(98)00242-X

Zhang, C., Wang, Y., Zhang, L., and Zhou, H. (2012). A fuzzy inference method based on association rule analysis with application to river flood forecasting. Water Sci. Technol., 66(10), 20902098. http://dx.doi.org/10.2166/wst.2012.420

Zhang, K. and Achari, G. (2010). Correlations between uncertainty theories and their applications in uncertainty propagation. In Furuta, H., Frangopol, D.M., \& Shinozuka, M. (Eds.), Safety, reliability and risk of structures, infrastructures and engineering systems, pp. 1337-1344, Taylor \& Francis Group, London, UK. http://dx.doi. org/10.1201/9781439847657-c20

Zhang, K., Li, H., and Achari, G. (2009). Fuzzy-stochastic characterization of site uncertainty and variability in groundwater flow and contaminant transport through a heterogeneous aquifer. $J$. Contam. Hydrol., 106(1), 73-82. http://dx.doi.org/10.1016/j.jconhyd.2009.01.003 